\title{
Experimental Study on Seismic Response of a Large-Span and Column-Free Subway Station in Composite Strata
}

\author{
Tingjin Liu $\mathbb{D}^{1,2}$ Siyuan Zheng, ${ }^{3}$ Xinwei Tang $\mathbb{D}^{2,3}$ and Weixing $\mathrm{Xu}^{3}$ \\ ${ }^{1}$ State Key Laboratory of Subtropical Building Science, South China University of Technology, Guangzhou 510640, China \\ ${ }^{2}$ South China Institute of Geotechnical Engineering, South China University of Technology, Guangzhou 510640, China \\ ${ }^{3}$ School of Civil Engineering and Transportation, South China University of Technology, Guangzhou 510640, China
}

Correspondence should be addressed to Xinwei Tang; cttangxw@scut.edu.cn

Received 19 June 2019; Revised 21 August 2019; Accepted 17 September 2019; Published 13 October 2019

Academic Editor: Luigi Di Sarno

Copyright (c) 2019 Tingjin Liu et al. This is an open access article distributed under the Creative Commons Attribution License, which permits unrestricted use, distribution, and reproduction in any medium, provided the original work is properly cited.

\begin{abstract}
In this paper, a shaking table test was conducted to investigate the seismic response of the large-span and column-free subway station in the upper-soft and lower-hard strata. The acceleration of the structure and the soil, the dynamic soil pressure, and the strain response of the subway station were obtained and analyzed. The results demonstrate the reasonable test design as the boundary effect was eliminated. The seismic response of the structure and soil became more severe as the acceleration amplitude of the input motion increased. It is indicated that possible shear damage of the soil and irreversible plastic deformation of the structure might have occurred as the test proceeded. The soft clay had a greater effect on the structure than that of the artificial rock. For the model structure, the tensile strain amplitude in the support region was larger than that in the midspan region. The support regions of the roof slab, lateral wall, and middle slab were the vulnerable components of the model structure during earthquakes.
\end{abstract}

\section{Introduction}

With the merits of improving space utilization efficiency and architectural aesthetics, a new type of subway station, a large-span and column-free subway station, is to be built in Guangzhou Metro Line 11 for better services and more comfortable travel. The large-span and column-free subway station has a platform width larger than $10 \mathrm{~m}$, in which the columns of the public area are eliminated, providing more space and visual enjoyment for passengers. However, as the large-span and column-free subway station is to be built in composite strata with an upper soft zone and lower hard zone (as shown in Figure 1), the lateral displacement of the station might be greater than that in single strata, which is a great threat to the station during earthquakes. Thus, the seismic performance of the station in composite strata remains uncertain. In addition, the existing research on that type of subway station is rare, and the design standards are far from meeting the construction requirements. Hence, the seismic performance of such a large-span and column-free subway station needs more attention.

The collapse of the Daikai subway station during the Great Hanshin Earthquake [1] has attached more attention to the seismic performance of underground structures. Since then, a series of centrifuge and shaking table tests have been carried to understand the aseismic ability and damage mechanism of underground subway stations. Nishiyama et al. [2] proposed a three-level seismic design method for open-trench tunnels based on shaking table tests on subway tunnels and numerical analysis. Iwatate et al. [3, 4] conducted several shaking table tests on underground subway stations. It was contended that the Daikai subway station suffered great horizontal shear force from the surrounding soil, and shear failure caused the collapse of the columns after damage to the roof slab. Ohtomo et al. [5, 6] performed shaking table tests on underground reinforced concrete structures and believed that the deformation of the surrounding soil controlled the deformation of the 


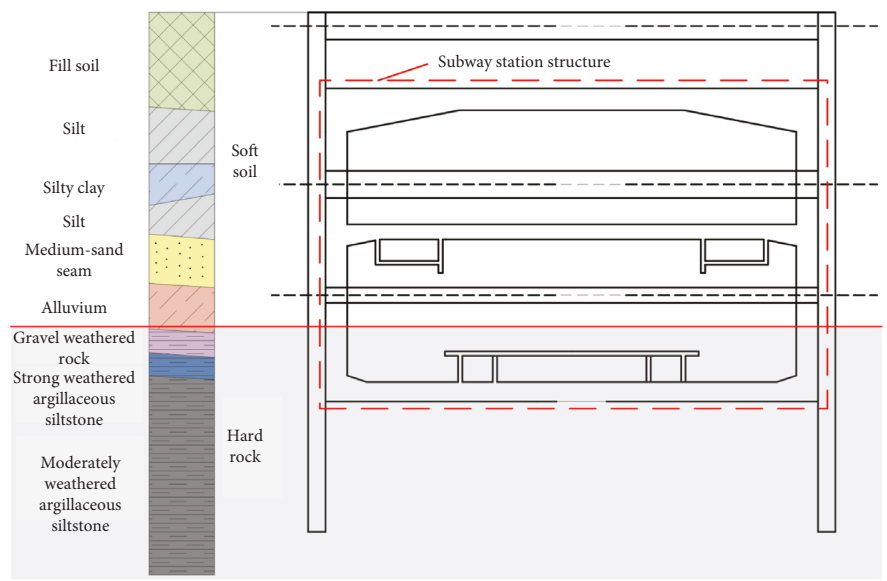

(a)

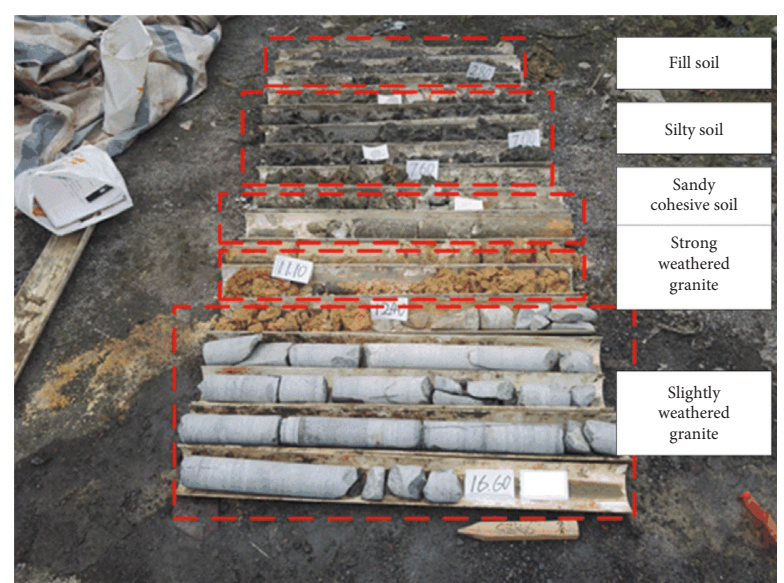

(b)

FIgURE 1: Large-span and column-free subway station in composite strata. (a) The proposed subway station and its surrounding strata. (b) On-site drilling of soil samples.

underground structure. Moreover, through a shaking table test on an underground structure on a liquefiable foundation, Tamari and Towhata [7] verified that the seismic response of the liquefiable foundation-underground structure system was greatly affected by the natural vibration period of both the site and the underground structure as well as the swelling property of the backfill soil. Che et al. [8] conducted a shaking table test on buried culvert and found that the culvert was largely subjected to lateral earth pressure during an earthquake. Moss and Crosariol [9] performed a series of shaking table tests on the basis of tunnels in the Bay Area Rapid Transit System in San Francisco and compared the test results with the numerical analysis results, concluding that the existing design method overestimates the racking distortion of soft soil-rigid structures.

Furthermore, shaking table tests on different types of subway stations and soft or liquefiable soil sites are conducted to comprehensively understand the seismic performance of the subway stations. Chen et al. [10-14] carried out shaking table tests on the three-story three-span station and three-arch-type station under soft or liquefiable foundations. The failure mechanism and damage process of these stations under soft or liquefiable foundations were systemically revealed. In addition, macroscopic phenomena during an earthquake were perfectly reproduced, such as sand boil, surface crack on the ground, and uplift of the subway station. Tao et al. $[15,16]$ conducted shaking table tests on the twostory two-span station and $Y$-shaped column double-layer station and studied the seismic response of shallow-buried subway stations. Chen et al. [17] investigated the effect of pulse-like ground motion on a multistory subway station through shaking table tests, proposing that central columns with a large story height are vulnerable components of multistory subway stations. Zhuang et al. $[18,19]$ studied the seismic response of large underground structures buried in soft or liquefiable soil through a shaking table test and concluded that the soft or liquefiable soil and the subway station interacted with each other. Qin and Chouw [20] conducted the model test about the effect of structure- footing-soil interaction of the structures on both dry sand and saturated soils and found out that the mainshock and aftershock had quite a different effect on the response of the structures. Ma et al. [21] proposed a vibration reduction method for a subway station in soft ground according to the dynamic response of the stations and the surrounding structures.

Although numerous shaking table tests on subway stations have been conducted, model tests about the large-span and column-free subway station have not yet been conducted. In addition, the shaking table tests on subway stations in composite strata are rare. Hence, in this paper, a shaking table test was carried out on the large-span and column-free subway station in upper-soft and lower-hard composite strata to understand the seismic performance of that station. The experimental setup and test design are explained. Then, the test results are analyzed, including acceleration, dynamic soil pressure, and strain response.

\section{Experimental Setup}

2.1. Shaking Table. The test was conducted using the shaking table facility at the State Key Laboratory of Subtropical Building Science, South China University of Technology. The table could be input with three-dimensional motions with six degrees of freedom. The shaking table consisted of a $4 \mathrm{~m} \times 4 \mathrm{~m}$ platform capable of carrying a maximum payload of 20 tons. The working frequency ranges from 0.1 to $50 \mathrm{~Hz}$. The shaking table vibrates with a maximum horizontal acceleration of $1.0 \mathrm{~g}$ and a maximum vertical acceleration of $1.0 \mathrm{~g}$.

2.2. Model Box. To minimize the soil box effect, a laminar shear box was designed in this test, as shown in Figure 2, which is a single horizontal-layer shear box with a net size of $3.2 \mathrm{~m}$ long, $2.0 \mathrm{~m}$ wide, and $1.4 \mathrm{~m}$ high and a total weight of $3.5 \mathrm{t}$. The laminar shear box consisted of 11 horizontal rectangular hollow steel-pipe layers, which had a cross 
section of $120 \mathrm{~mm} \times 60 \mathrm{~mm}$ and a wall thickness of $4 \mathrm{~mm}$. The layers were connected through 4 roller bearings with a diameter of $80 \mathrm{~mm}$, and the clearance between them was $10 \mathrm{~mm}$. The layers could move relative to one another according to the deformation of the soils inside.

To prevent large deformation of the bottom plate of the laminar box during the hoisting process, a short side triangle stiffening rib was set up to enhance the rigidity of the bottom plate. On the two side faces parallel to the shaking direction, two portal-type frames, each made of the two upright columns and X-type hollow steel pipes, were installed to restrict the deformation of the soils and box perpendicular to the shaking direction. Each column contacted the box through roller bearings, reducing the friction between the columns and the box. Additionally, the bearings could be fine tuned to limit the deformation of the box. On the two side faces perpendicular to the shaking direction, two groups of fixed axes were separately set up on the top and bottom of the box, in which a thickness-adjustable steel plate could be embedded to avoid bending deformation of the box and soils.

2.3. Instrumentation. To study the dynamic response of the structure and the dynamic soil-structure interaction, 32 accelerometers, 46 strain gauges, and 12 soil pressure gauges were used in this test. The accelerometer was TLD393B04 produced by PCB Piezotronics, Inc., with a sensitivity of $( \pm 10 \%) 1000 \mathrm{mV} / \mathrm{g}$, a measurement range of $\pm 5 \mathrm{~g} \cdot \mathrm{pk}$, and a frequency range of $( \pm 5 \%) 0.06$ to $450 \mathrm{~Hz}$. The strain gauge was a strip-like uniaxial strain gauge with a length of $8 \mathrm{~mm}$. The soil pressure gauge was full-bridge sensors with a diameter of $25 \mathrm{~mm}$, a thickness of $7 \mathrm{~mm}$, and a measuring range of $50 \mathrm{kPa}$. The data acquisition instrument with 64 channels was produced by DEWETRON, and the rates of sampling for strain and accelerometer acquisition used in this test were $500 \mathrm{~Hz}$.

\section{Test Design}

3.1. Similitude Ration. The prototype structure is a largespan column-free subway station with a height of $14.41 \mathrm{~m}$ and a width of $22.70 \mathrm{~m}$. Limited by the dimensions and the bearing capacity of the shaking table, a model structure was adopted in the test. To possibly ensure that the model structure reflects the dynamic performance of the prototype structures, the similitude ration of the model structure, including geometry, material properties, and dynamic characteristics, should be determined. However, it is difficult to make all the parameters satisfy the scale factors for both the structure and the composite foundation.

Herein, the scale factors of the elastic modulus, geometry, and acceleration were first determined as the basic parameters, while the scale factors of the other parameters could be deduced from the three basic parameters according to the Buckingham Law [22]. According to the size of the shaking table, the geometry scale factor was set as $1 / 30$. The elastic modulus scale factor was $1 / 4$, and the acceleration scale factor was 1 . The scale factors of the model structure are listed in Table 1.

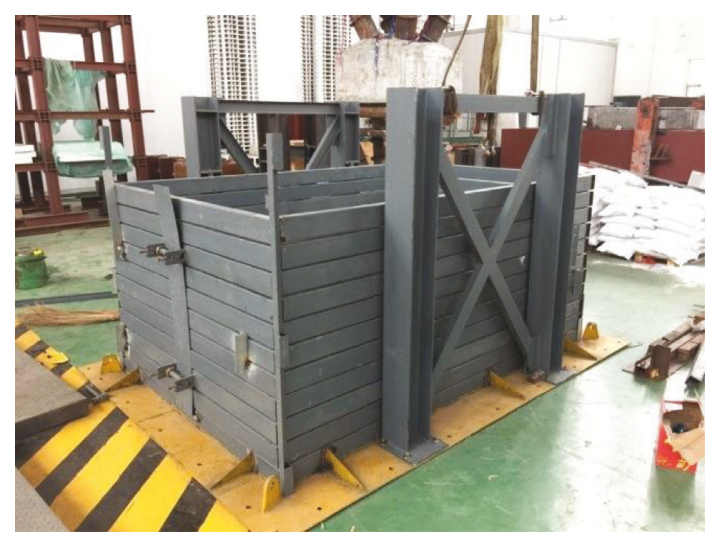

Figure 2: Laminar box.

TABLE 1: Scale factors of the model structure.

\begin{tabular}{lccc}
\hline Type & $\begin{array}{c}\text { Physical } \\
\text { quantities }\end{array}$ & Symbol & $\begin{array}{c}\text { Scale } \\
\text { factor }\end{array}$ \\
\hline Geometric & Geometry & $\lambda_{l}$ & $1 / 30$ \\
properties & $\begin{array}{c}\text { Displacement } \\
\text { Inertia moment }\end{array}$ & $\begin{array}{c}\lambda_{r}=\lambda_{l} \\
\lambda_{I}=\lambda_{l}^{4}\end{array}$ & $1 / 30$ \\
& Density & $\lambda_{\rho}=\lambda_{E} / \lambda_{l} \lambda_{a}$ & 3.75 \\
\hline Material & Elastic modulus & $\lambda_{E}$ & $1 / 4$ \\
properties & Mass & $\lambda_{m}=\lambda_{d} \cdot \lambda_{l}^{3}$ & $3.75 / 30^{3}$ \\
& Frequency & $\lambda_{\omega}=1 / \lambda_{t}$ & 7.752 \\
Dynamic & Acceleration & $\lambda_{a}$ & 2 \\
properties & Time & $\lambda_{t}=\left(\lambda_{l} / \lambda_{a}\right)^{0.5}$ & 0.129 \\
& Stress & $\lambda_{\sigma}=\lambda_{l} \cdot \lambda_{a} \cdot \lambda_{d}$ & 0.25 \\
\hline
\end{tabular}

3.2. Model Structure. To present the nonlinear mechanical properties of the reinforced concrete in the experimental test, microconcrete and galvanized steel wires were used as the structure material. The microconcrete consisted of coarse and fine aggregates, that is, gravel with a particle size of $2.5 \mathrm{~mm} \sim 5.0 \mathrm{~mm}$ and sand with a particle size of $0.315 \mathrm{~mm} \sim 2.5 \mathrm{~mm}$. According to the scale factor, the mix proportion for the microconcrete was determined. Meanwhile, the properties of the microconcrete were measured through a series of material tests, and the scale factor of elastic modulus was adjusted according to the results of the material tests. The mix proportion and mechanical properties of the microconcrete are listed in Table 2.

The prototype station has a platform width of $13 \mathrm{~m}$ and is column free. According to the geometric scale factor, the dimensions of the model structure were determined, as shown in Figure 3. Considering the width of the laminar box perpendicular to the shaking direction, the length of the model structure was determined to be $1500 \mathrm{~mm}$. The model structure was sealed with an $8 \mathrm{~mm}$ thick organic glass plate to prevent the soil from coming into the model, which stuck on the edge of the model structure with hot melts and was fixed with glass cement around the hole put through the connection wire.

To make the gravity and inertia effect of the model structure in accordance with those of the prototype structure, additional artificial masses were uniformly distributed 
TABLE 2: Mix proportion and mechanical properties of the microconcrete.

\begin{tabular}{lccc}
\hline Sample & Mix proportion & Uniaxial compressive strength (MPa) & Elastic modulus (MPa) \\
\hline 1 & Water : cement : lime : sand $=0.5: 1: 0.58: 5$ & 10.6 & 8467.3 \\
2 & & 11.3 & 9561.6 \\
3 & & 10.3 & 8214.2 \\
4 & 10.9 & 9319.5 \\
Average & & 10.8 & 8890.7 \\
\hline
\end{tabular}

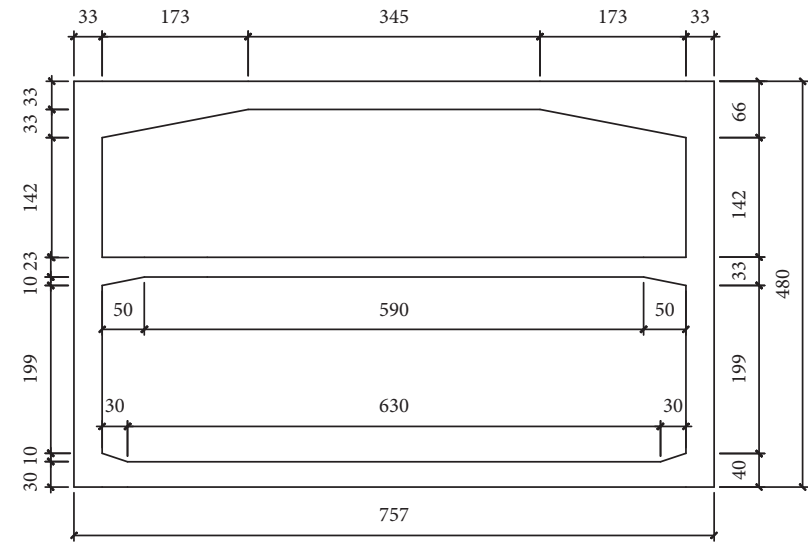

(a)

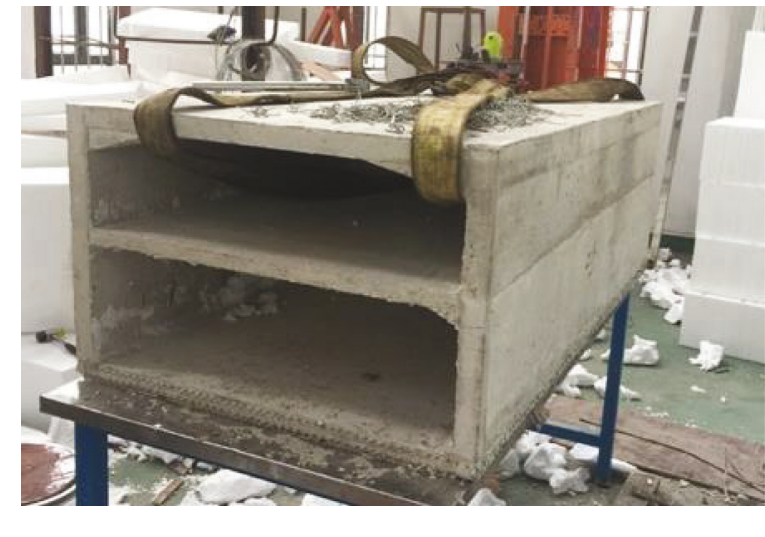

(b)

Figure 3: Model structure. (a) Dimensions of the model structure cross section (unit: mm). (b) Physical map.

on the two stories of the model structure by employing iron blocks, each with a standard mass of $2.5 \mathrm{~kg}$. Moreover, each block was fixed with hot melts to prevent the blocks from sliding and hitting the sensors in the model structure.

Based on the reinforcement of the prototype structure and the principle of elastic modulus equivalence, the reinforcement of the model structure was determined, as shown in Figure 4. There were three diameters of the galvanized steel wire used in the model structure, $\Phi 1, \Phi 2$, and $\Phi$ 2.6. The tensile yield strength and elastic modulus of the galvanized steel wire were $165 \mathrm{MPa}$ and $1.21 \times 10^{5} \mathrm{MPa}$, respectively, according to the material tests (Figure 5).

3.3. Model Soil. The gravity scale factor of the soil was ignored in this test. The model soil was simplified into two layers based on practical geologic conditions. The top layer was soft clay, while the bottom layer was artificial rock, with a thickness of $0.65 \mathrm{~m}$ and $0.58 \mathrm{~m}$, respectively. The layout of the model soil is shown in Figure 6.

The clay used in the top layer was taken on-site in Guangzhou, while the artificial rock materials used in the bottom layer were artificially prepared with quartz sand, barite powder, water, gypsum, and glycerol, with mass ratios of $28.1 \%, 46.5 \%, 15.7 \%, 8.8 \%$, and $0.9 \%$, respectively. The mechanical parameters of the clay and the artificial rock material were obtained through soil mechanics tests (as shown in Figure 7) and are listed in Table 3. Herein, the elastic modulus of the artificial rock material was approximately 6 times that of the clay.

The artificial rock material was mixed quickly and evenly in the laboratory and deposited into the laminar box layer by layer, which was later maintained for 48 hours to reach its required mechanical properties. Then, the soft clay was placed above the artificial rock layer by layer. Each layer was compacted to a thickness of $15-20 \mathrm{~cm}$. After completing the filling process, the clay was solidified for approximately 20 hours to ensure that the soil parameters were consistent.

3.4. Sensor Layout. Based on previous numerical analysis of the seismic response of the structure, an observation plane was placed at the middle of the model structure to collect data. The collected data included the acceleration of the model structure and soil, the strain of the model structure, and the dynamic soil pressure on the sidewall of the model structure.

As presented in Figure 8, the accelerometers A1-A13 were placed to study the propagation of the seismic waves in the soil and A14-A16 were placed to record the dynamic response of the subway structure. As shown in Figure 9, the strain gauges S1-S14 and the soil pressure gauges P1-P6 were fixed on the subway structure.

3.5. Test Cases. Three typical ground motions were selected to investigate the effects of different seismic waves on the subway structure, including the Kobe ground motion from Japan, the El Centro ground motion from the United States, and the Guangzhou artificial wave. The acceleration-time histories and Fourier spectra of the three records are presented in Figure 10.

The shaking direction was parallel to the cross section of the model structure. White noise was input to explore the difference in dynamic characteristics of the model structure 


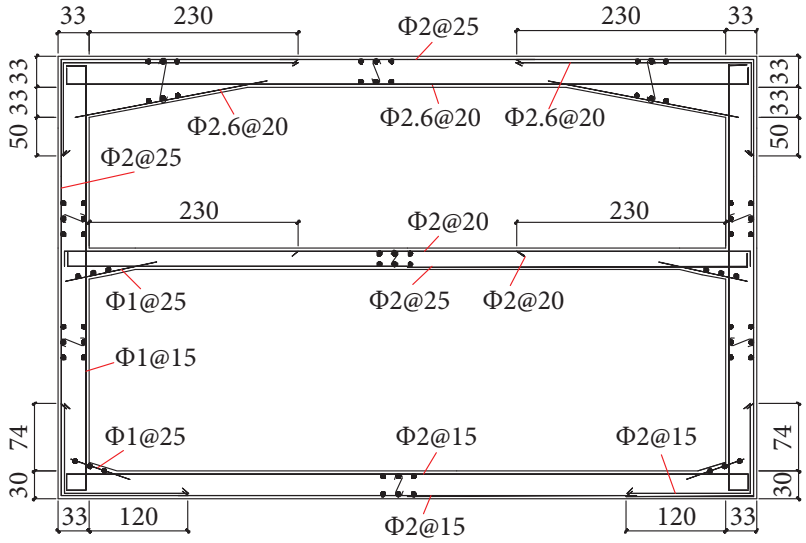

(a)

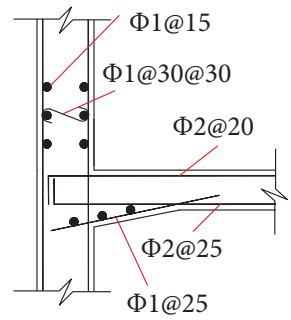

(c)

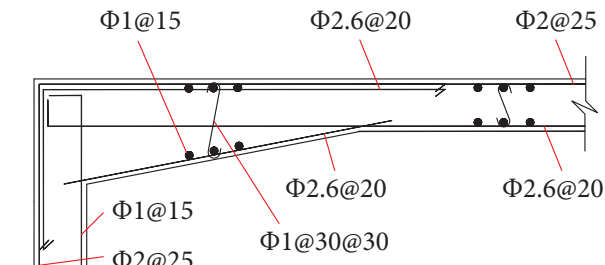

(b)

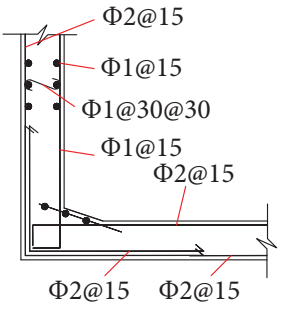

(d)

Figure 4: Reinforcement of the model structure (unit: $\mathrm{mm}$ ). (a) The entire section. (b) Details between the roof slab and the lateral wall. (c) Details between the middle slab and the lateral wall. (d) Details between the bottom slab and the lateral wall.

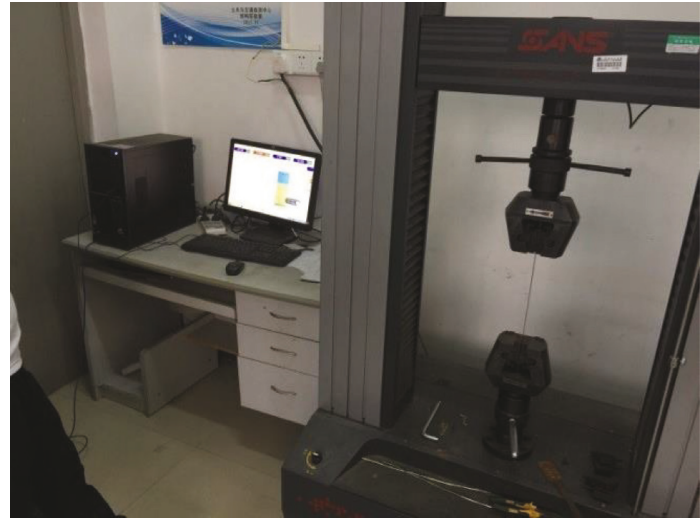

FIGURE 5: Tensile test for the galvanized steel wire.

such as the natural frequency and damping ratio. The ground motions were scaled to six levels, namely, $0.1 \mathrm{~g}, 0.2 \mathrm{~g}$, $0.3 \mathrm{~g}, 0.4 \mathrm{~g}, 0.6 \mathrm{~g}$, and $0.8 \mathrm{~g}$. The loading conditions are listed in Table 4.

\section{Test Results and Analysis}

4.1. Boundary Effect Validation. In the shaking table test for the underground structure, the model box was used to simulate the semi-infinite foundation. However, the seismic wave would be reflected in the boundary of the box, causing offset or overlaid seismic waves during the test and affecting the actual response of the model structure and soil. Thus, the boundary effect of the model box needs to be verified.

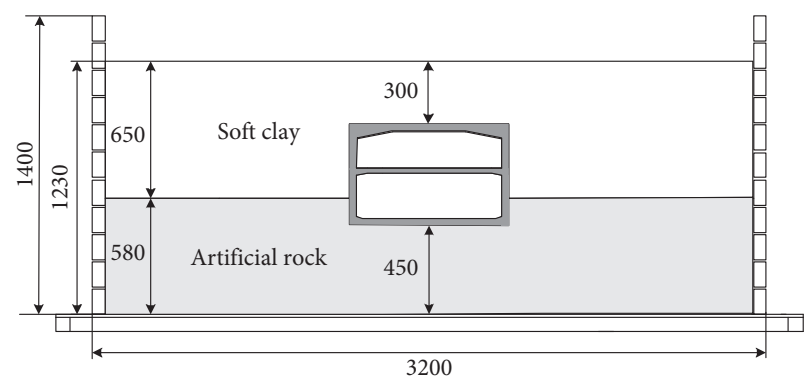

FIgURE 6: Layout of the model soil (unit: $\mathrm{mm}$ ).

Figure 11 presents the time histories of the accelerometers A5-A7 and A11-A13 under the El Centro ground motion with $0.2 \mathrm{~g}$ acceleration amplitude. According to Figure 11, the time-history curves of acceleration at the accelerometers A5-A7 showed the same trend. In addition, the peak values of A5-A7 were $0.10 \mathrm{~g}, 0.11 \mathrm{~g}$, and $0.11 \mathrm{~g}$, respectively, almost the same as each other. Similar rules could be found from the accelerometers A11-A13. Therefore, the boundary effect could be eliminated in the test.

Furthermore, by carrying out the white noise test on the empty model box, the natural frequency of the box was $2.21 \mathrm{~Hz}$. Meanwhile, the natural frequency of the structurefoundation model system tested in the shaking table test was greater than $6.5 \mathrm{~Hz}$. The difference between the natural frequency of the box and the structure-foundation model system indicates that the resonance response between them is insignificant. 


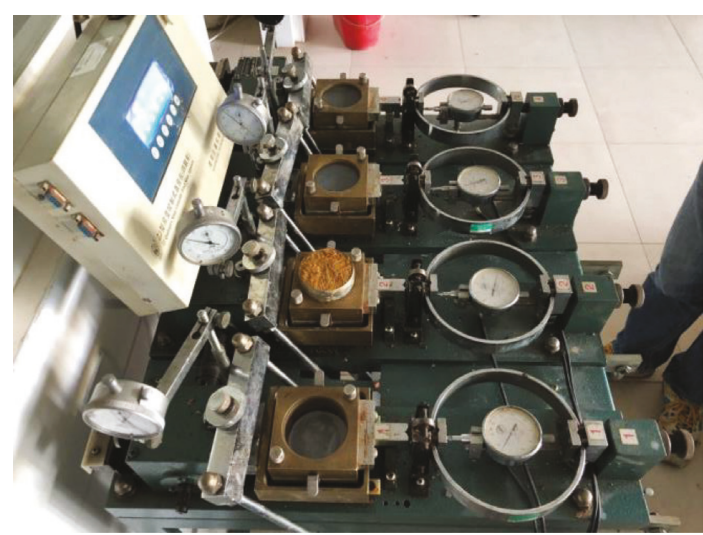

(a)

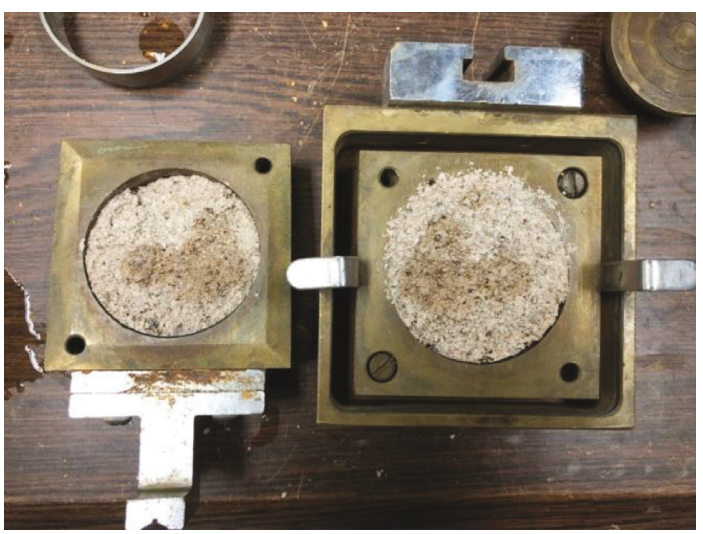

(b)

FIGURE 7: Soil mechanics tests for the model soil. (a) Direct shear test for the soft clay. (b) Shearing test for the artificial rock.

TABLE 3: Mechanical parameters of the model soil.

\begin{tabular}{lccccc}
\hline Soil type & Density $\left(\mathrm{g} / \mathrm{cm}^{3}\right)$ & Modulus $(\mathrm{MPa})$ & Internal friction angle $\left(^{\circ}\right)$ & Cohesion $(\mathrm{kPa})$ & Water content $(\%)$ \\
\hline Soft clay & 1.65 & 10.5 & 14.0 & 22.4 & 17.7 \\
Artificial rock & 2.18 & 61.4 & 46.4 & 1.8 & - \\
\hline
\end{tabular}

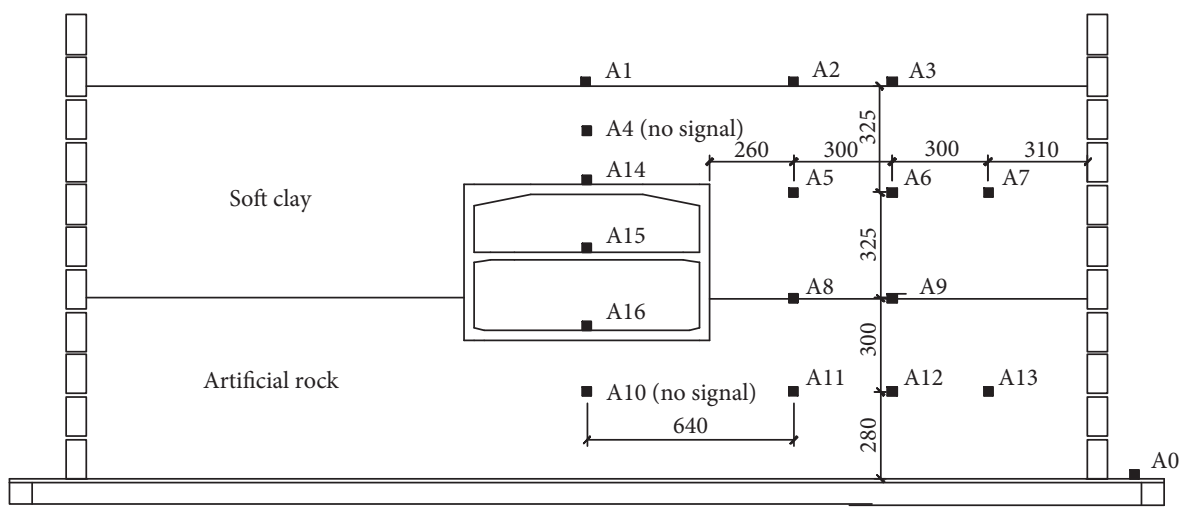

FIGURE 8: Layout of the accelerometers in the model structure and soil (unit: $\mathrm{mm}$ ).

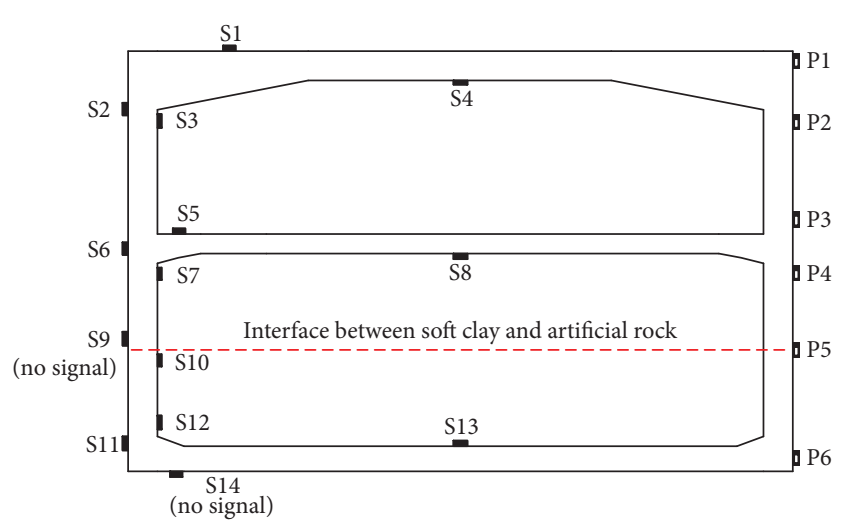

FIGURE 9: Layout of the strain and soil pressure gauges in the model structure.

Overall, it can be concluded that the test design was reasonable and its results were reliable to reveal the seismic response of the model structure and soil.
4.2. Acceleration Response of the Model Soil. The peak acceleration amplification factor is defined and analyzed in the acceleration response of the model soil and structure. It is obtained through the peak acceleration of the model divided by the input acceleration amplitude of the shaking table.

Figure 12 presents the peak acceleration amplification factors at different depths in the model soil in cases C6-C8; that is, the acceleration amplitude of the input ground motion is $0.10 \mathrm{~g}$. There were different variations in the peak acceleration amplification factor in the soft clay or the artificial rock. For the input motion of the El Centro record, the peak acceleration amplification factor decreased from the bottom to the top in the artificial rock, while increased from the bottom to the top in the soft clay. However, for the input motion of the Kobe record and the Guangzhou artificial wave, the peak acceleration amplification factor increased from the bottom to the top in the model soil, reaching 1.349 and 1.214, respectively, of which a larger increment was observed in the soft clay than in the artificial rock. Moreover, because of the richer low-frequency 

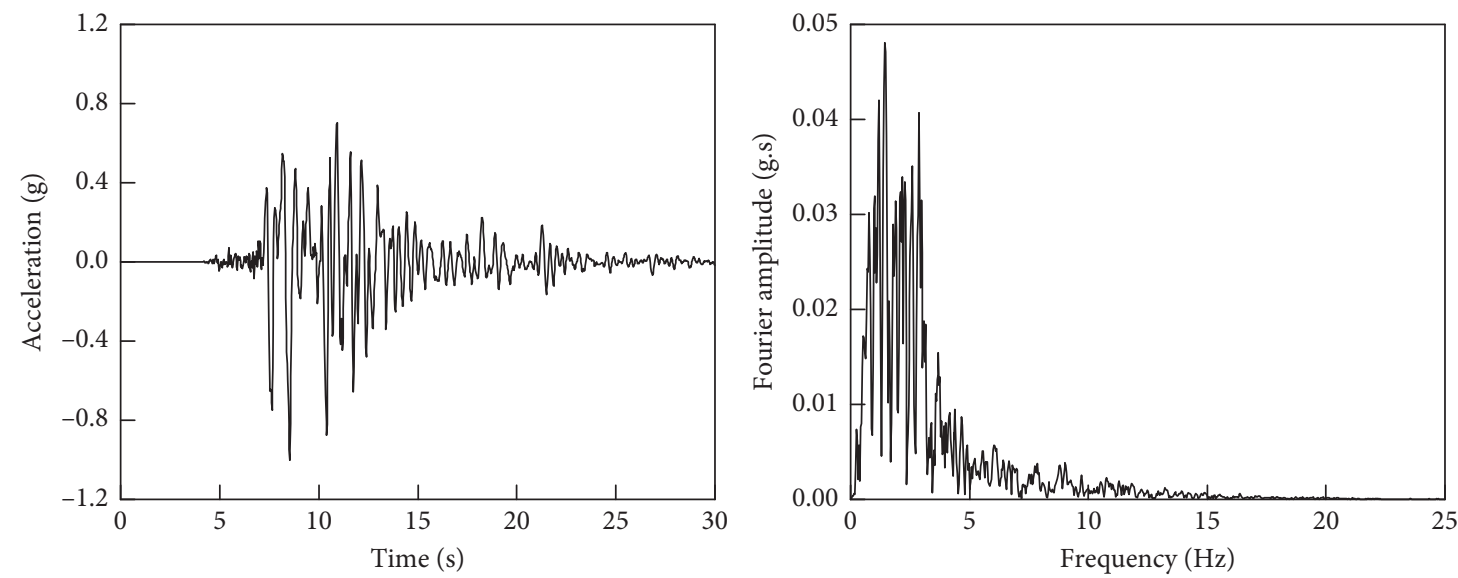

(a)
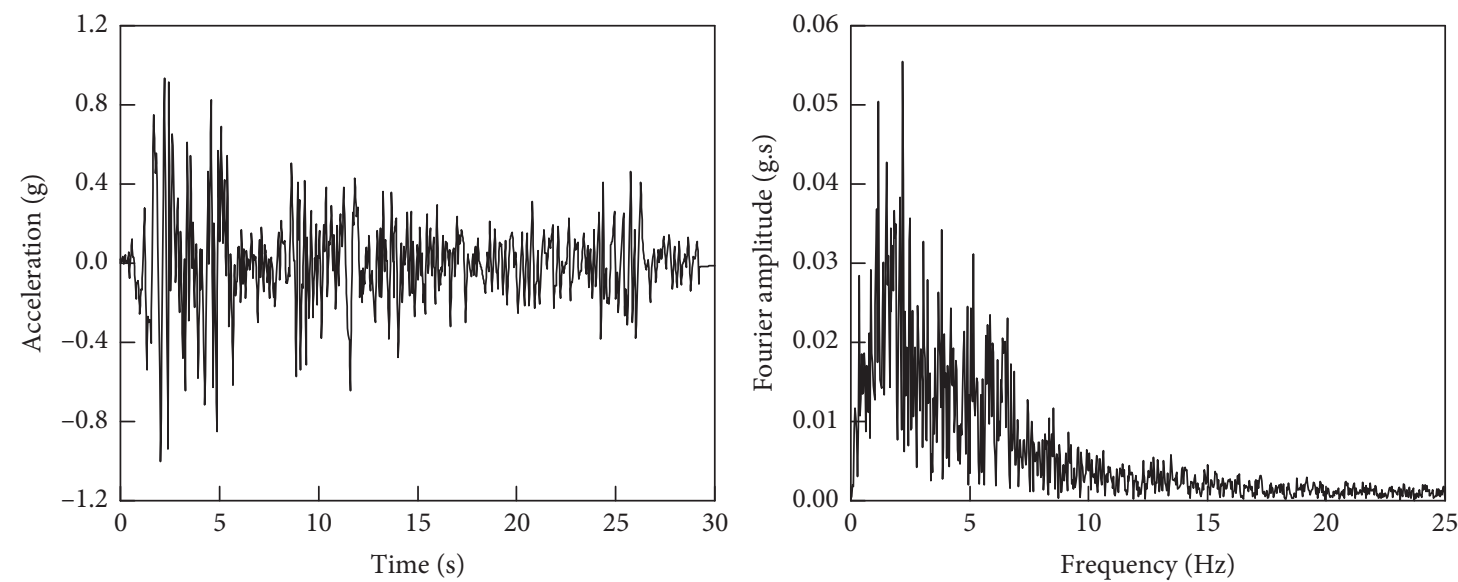

(b)
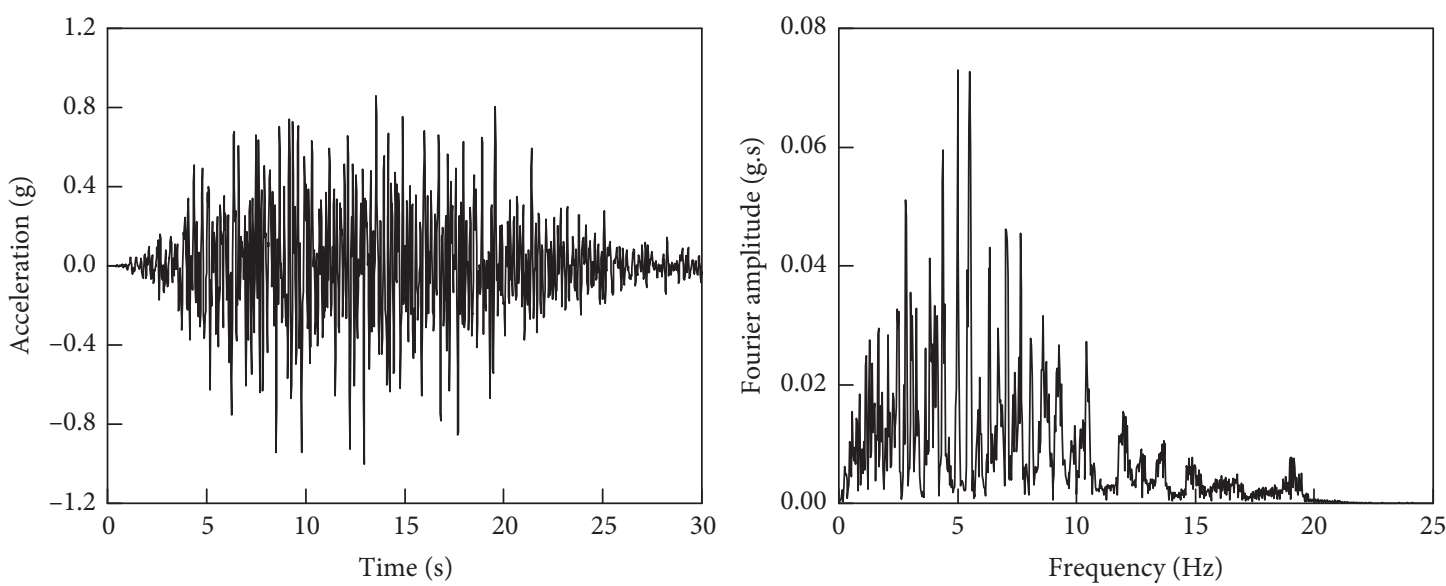

(c)

FIGURE 10: Ground motion acceleration-time histories and Fourier spectra input on the shaking table. (a) Kobe record. (b) El Centro record. (c) Guangzhou artificial wave.

components of the Kobe record, the response of the model soil was more sensitive under the Kobe record, resulting in the largest peak acceleration amplification factor under the Kobe record (as shown in Figure 12). Because of the differences in the filtering ability and the hysteretic energy dissipation of the model soil, the peak acceleration amplification factor in different soil layers or under different ground motions was also different.

The peak accelerations of the model soil at different depths under the Kobe ground motion are shown in Figure 13. The amplification effect was observed in all cases. The seismic response of the model soil was more violent as the 
TABLE 4: Test cases for the shaking table test.

\begin{tabular}{lcc}
\hline Case ID & Input wave & Acceleration amplitude $(\mathrm{g})$ \\
\hline C1 & White noise & 0.05 \\
C2 & Guangzhou wave & 0.10 \\
C3 & El Centro & 0.10 \\
C4 & Kobe & 0.10 \\
C5 & White noise & 0.05 \\
C6 & Guangzhou wave & 0.20 \\
C7 & El Centro & 0.20 \\
C8 & Kobe & 0.20 \\
C9 & White noise & 0.05 \\
C10 & Kobe & 0.30 \\
C11 & White noise & 0.05 \\
C12 & Kobe & 0.40 \\
C13 & White noise & 0.05 \\
C14 & Kobe & 0.60 \\
C15 & White noise & 0.05 \\
C16 & Kobe & 0.80 \\
C17 & White noise & 0.05 \\
\hline
\end{tabular}

acceleration amplification of the input motion increased. In addition, for the acceleration amplification of $0.60 \mathrm{~g}$ and $0.80 \mathrm{~g}$, the amplification effect was more obvious, especially in the soft clay. It is thought that shear failure gradually appeared in the model soil as the test proceeded.

4.3. Peak Acceleration of the Model Structure. The peak acceleration amplification factor of the model structure is shown in Figure 14. The peak acceleration amplification factor increased with the height of the structure, manifesting the amplification effect of the structure under three different ground motions. In addition, for the input motion of the Kobe record, the peak acceleration amplification factor was slightly greater than those of the El Centro record and the Guangzhou artificial wave, of which the peak acceleration amplification factor under the El Centro record was smallest. The aforementioned phenomena displayed the effect of input motions' frequency spectrum characteristics on the seismic response of the model structure. As shown in Figure 10, the frequency of the Kobe record was concentrated in the low-frequency range and thus was close to the natural frequency of the structure-foundation model system, resulting in more severe seismic response of the model structure. Moreover, as the model structure was easily deformed with the soft clay, the amplification effect was more evident on the structure buried in the soft clay than in the artificial rock.

The peak accelerations of the model structure under the Kobe record are shown in Figure 15. As the input acceleration amplitude increased, the peak accelerations of the model structure increased. The increment between adjacent acceleration amplitude values increased. Moreover, as shown in Table 5, the natural frequency of the model structure decreased as the test proceeded, showing stiffness degradation of the model structure. As the roof and middle slabs were located in the soft clay while the bottom slab was placed in the artificial rock, the increment of the peak acceleration in the roof slab was largest, followed by the middle slab and then the bottom slab, indicating larger deformation in the soft clay than in the artificial rock as the test proceeded.

4.4. Dynamic Soil Pressure of the Model Structure. The dynamic soil pressure between the model structure and the soil was measured through soil pressure gauges to investigate the variation of the soil-structure interaction pressure during an earthquake. Figure 16 depicts the dynamic soil pressure amplitude in cases of the Kobe ground motion. The dynamic soil pressure amplitude increased as the magnitude of the input motion increased except $\mathrm{P} 1$, and the "U-type" distribution of dynamic soil pressure was clearly observed.

Furthermore, it should be noted that different soil layers had evident effects on the soil pressure distribution. The turning point of the pressure distribution was observed at $\mathrm{P} 4$ near the soil interface, and the largest dynamic soil pressure amplitude emerged in the middle of the model structure (P3). Generally, the dynamic soil pressure in the soft clay was larger than that in the artificial rock on account of a different relative rigidity between the soil and the structure. The relative rigidity between the soft clay and the structure is greater than that between the artificial rock and the structure. When suffering the same seismic vibration, a greater relative deformation occurs between the soft clay and the structure, leading to a larger dynamic soil pressure in the soft clay.

Because of the disturbance of the soil during the test and the difficulties in accurately measuring the soil pressure, some of the dynamic soil pressure amplitude shown in Figure 16 had slight errors as the amplitude of the input motion increased. However, these errors only occurred locally and thus did not affect the distribution rules of the dynamic soil pressure.

4.5. Strain Response of the Subway Station Structure. As shown in Figure 9, the strain gauges were distributed in the midspan and support region of the model structure as well as in the soil interface region to investigate the vulnerable components of the subway station during an earthquake. Both the strain of the midspan and the strain of the support region of the structure components, that is, ten regions in total, were selected for analysis. Figure 17 presents the straintime histories of those ten regions of the model structure under the Kobe record. The peak strains as well as the residual strains increased with the input acceleration amplitude, of which the residual strains appeared since the input acceleration amplitude was larger than $0.30 \mathrm{~g}$. It is indicated that the irreversible plastic deformation of the model structure occurred.

As concrete structures usually suffer tensile failure, more attention is paid to the tensile strain of the model structure. Figure 18 shows the tensile strain amplitude on different regions of the model structure under the Kobe record. Because a certain error occurred in the strain acquisition system in case C10, a large strain error appeared in case C10. Thus, the tensile strain amplitude of case $\mathrm{C} 10$ was ignored in 


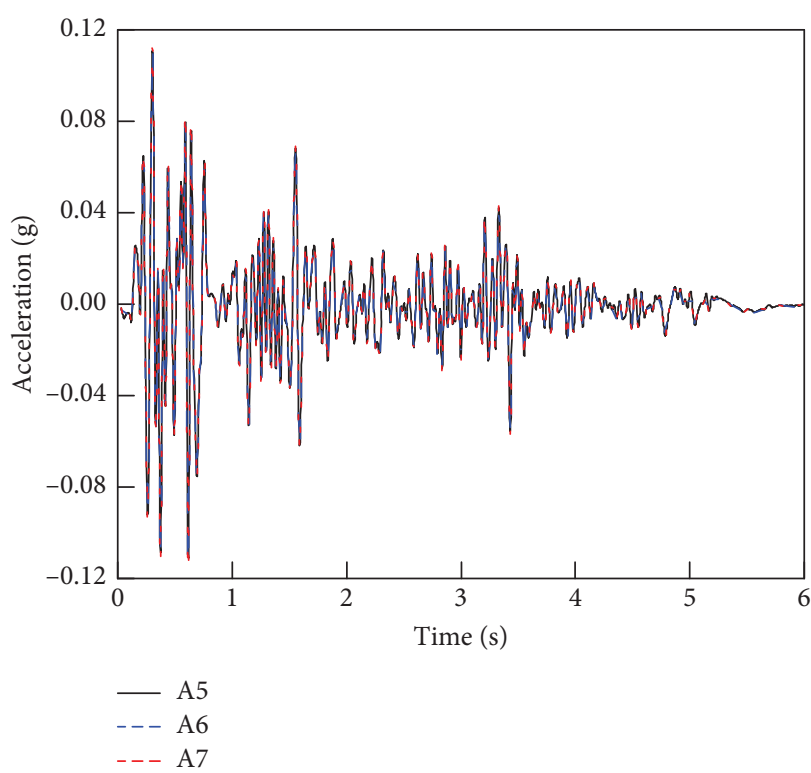

(a)

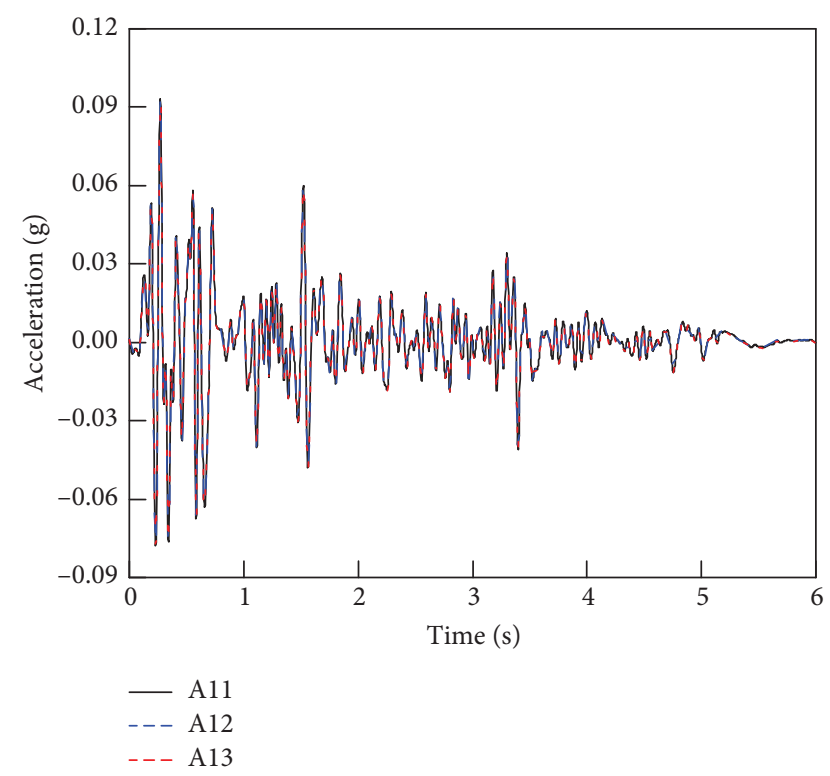

(b)

Figure 11: Time histories of acceleration for the accelerometers in case C7. (a) A5-A7. (b) A11-A13.

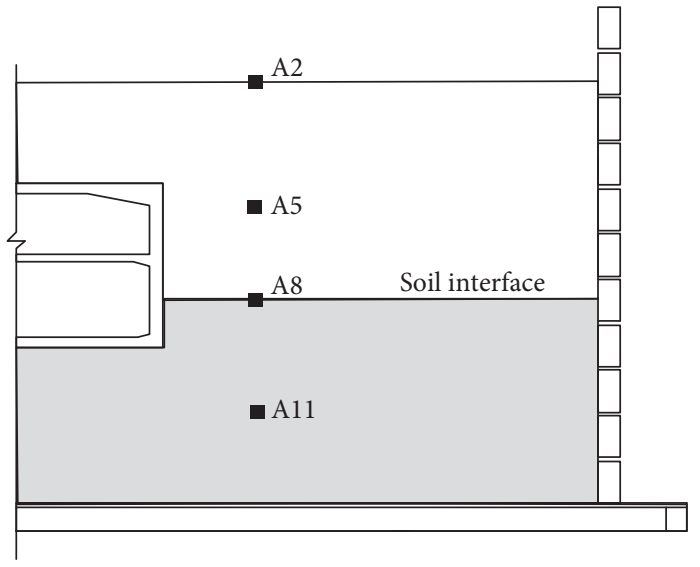

(a)

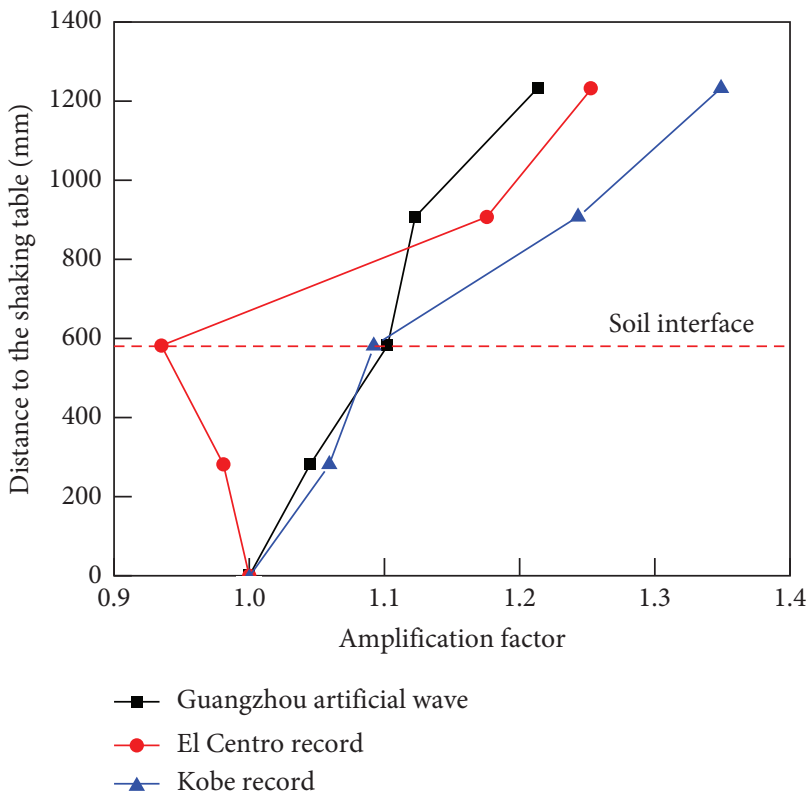

(b)

FIgURE 12: Peak acceleration amplification factor with the model soil depth in cases C6-C8.

Figure 18. For each component of the model structure, it is evident that the tensile strain amplitude in the support region was larger than that in the midspan region. It is because that the support region of the large-span and column-free station bears much more force as the span increases greater than that of the conventional station, resulting in a larger tensile strain in the support region during the seismic wave. Nevertheless, the tensile strain amplitude in both the midspan region and the support region almost linearly increased as the input acceleration amplitude increased. However, the increment of the tensile strain amplitude in the support region was larger than that in the midspan region, manifesting the irreversible deformation firstly occurring in the support region. Under the input acceleration amplitude of $0.80 \mathrm{~g}$, the largest tensile strain amplitude of $130.2 \mu \varepsilon$ appeared in the support region of the roof slab, followed by $100 \mu \varepsilon$ that appeared in the bottom support region of the lateral wall. In addition, the tensile strain in the support region of the middle slab was also larger than $100 \mu \varepsilon$. It is indicated that the support 

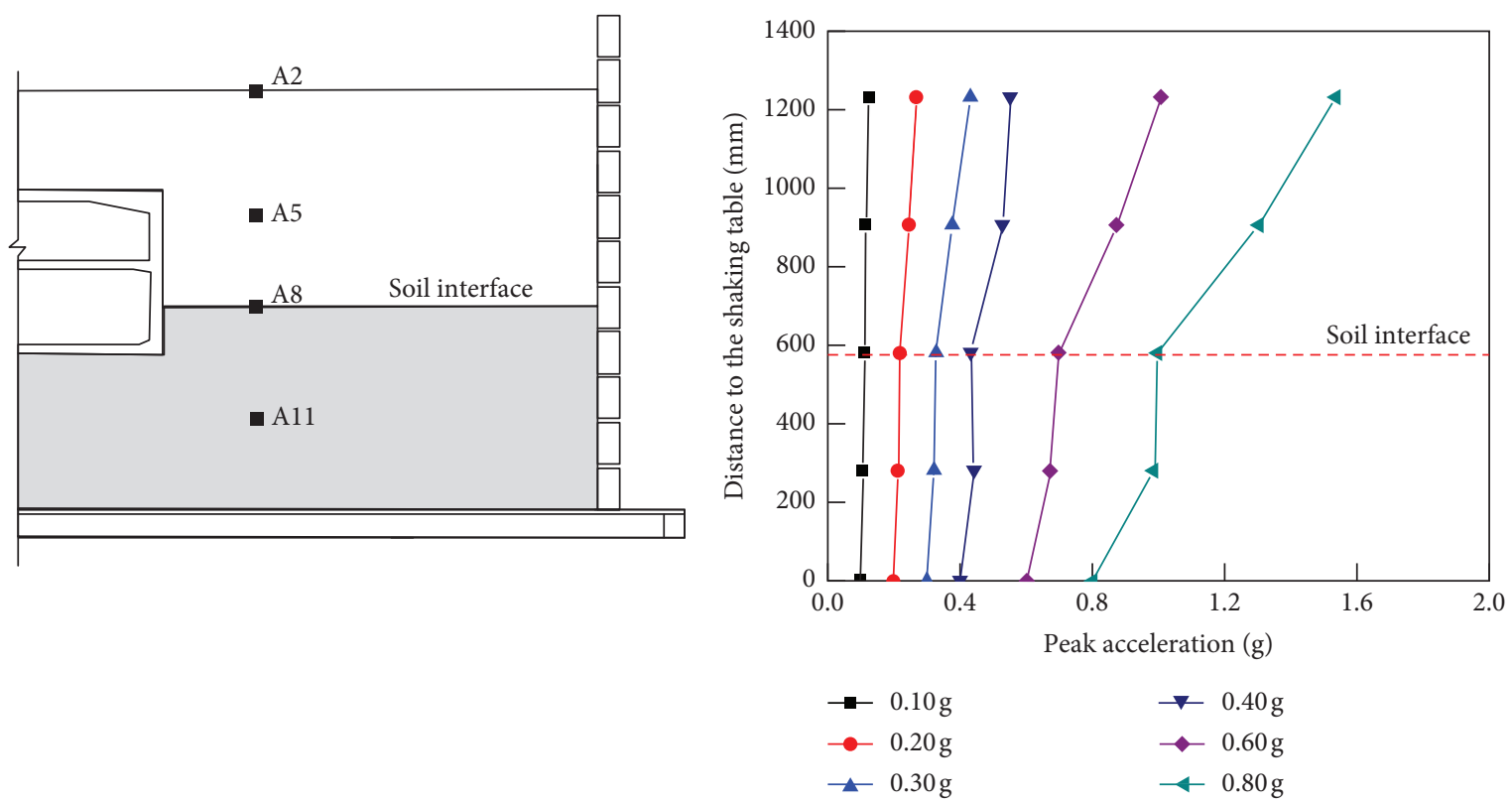

(a)

(b)

Figure 13: Peak accelerations of the model soil under the Kobe ground motion.
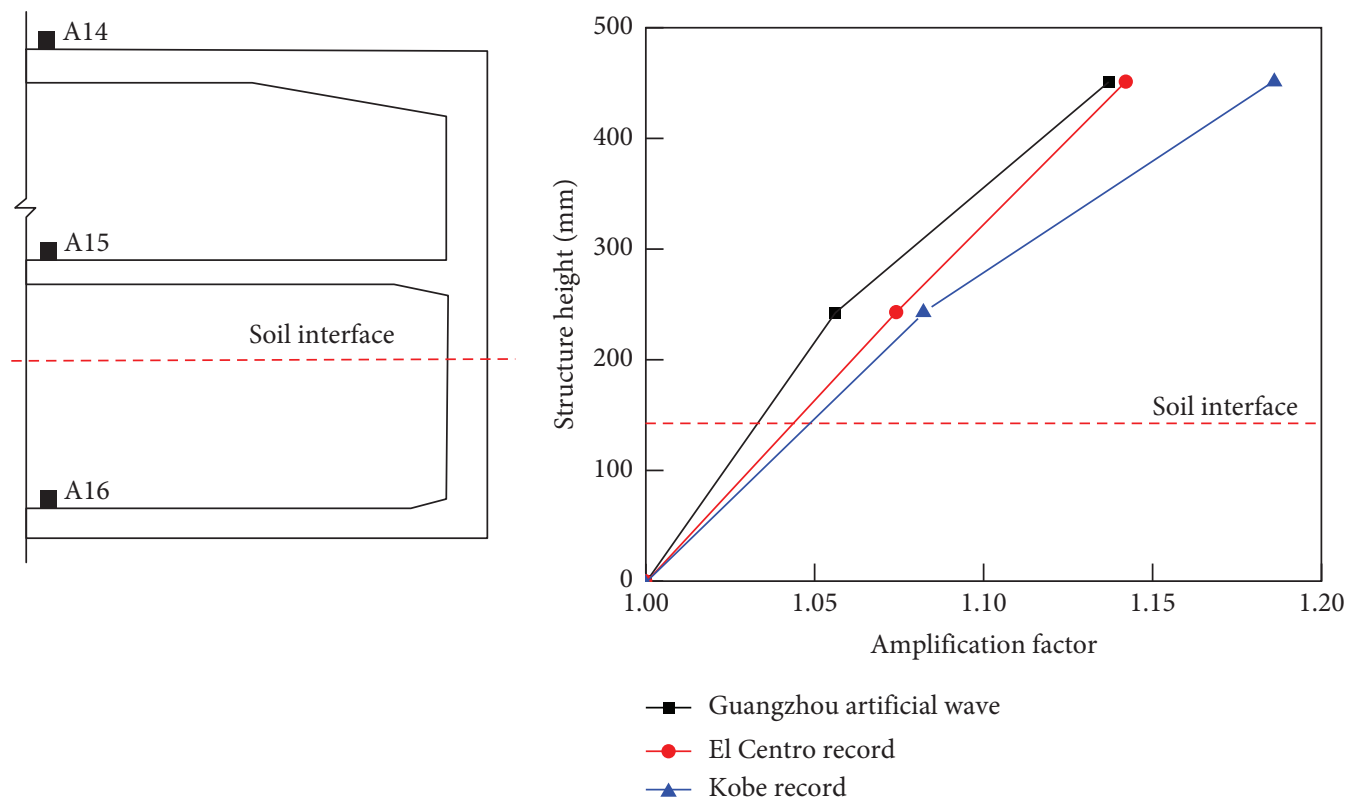

(a)

(b)

FIGURE 14: Peak acceleration amplification factor of the subway station structure in cases C6-C8.

regions of the roof slab, lateral wall, and middle slab might have severe damage during an earthquake, and strengthening measures should be applied.

\section{Concluding Remarks}

A shaking table test was conducted to study the seismic response of large-span and column-free subway stations in upper-soft and lower-hard composite strata. From the test data on the acceleration, the dynamic soil pressure, and the strain response and analysis, the main conclusions are drawn as follows:

(1) The test design was reasonable because of the elimination of the boundary effect and of different natural frequencies between the laminar shear box and the structure-foundation model system. The results of the test were reliable to reveal the seismic response of the model structure and soil. 

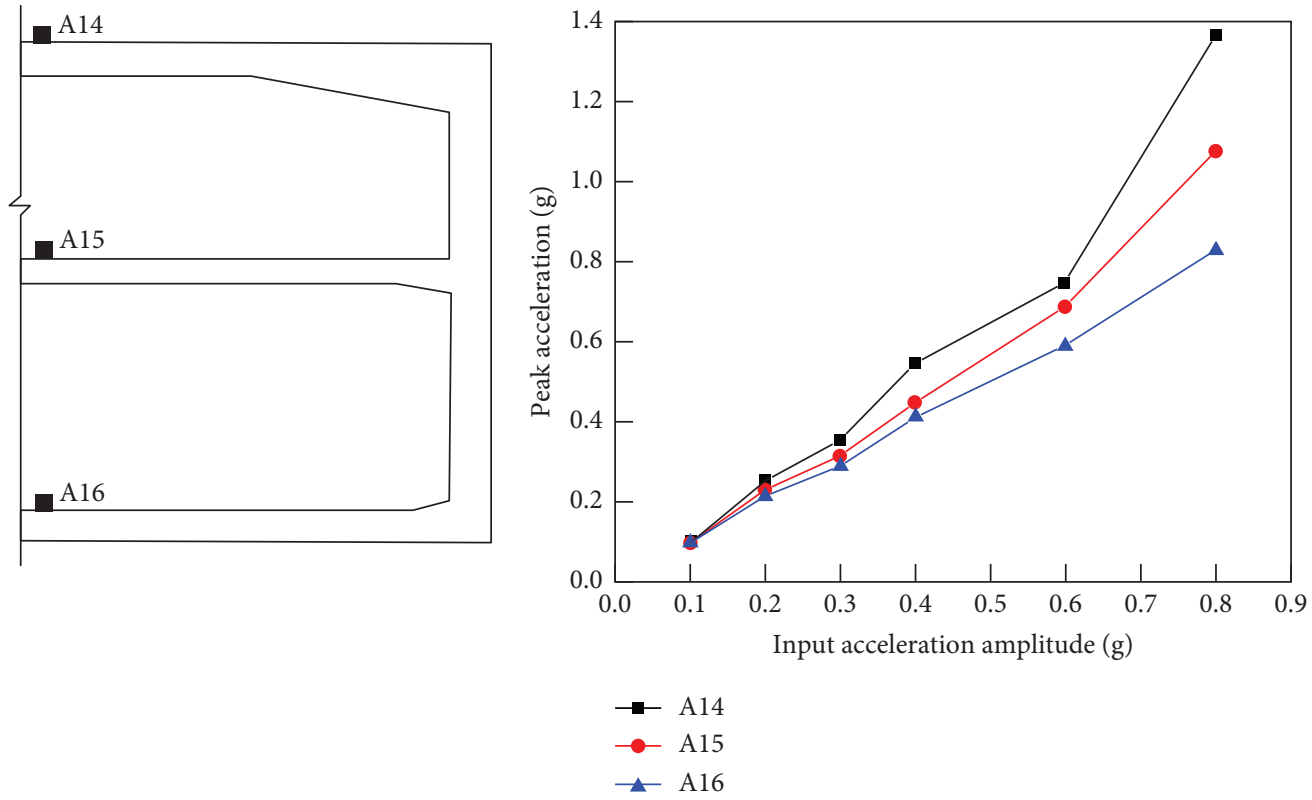

(a)

(b)

FIGURE 15: Peak accelerations of the subway station structure under the Kobe ground motion.

Table 5: Natural frequency of the model structure in different cases (unit: $\mathrm{Hz}$ ).

\begin{tabular}{lccc}
\hline Component & Case C1 & Case C13 & Case C17 \\
\hline Roof slab & 9.277 & 9.033 & 8.789 \\
Middle slab & 9.264 & 9.017 & 8.763 \\
\hline
\end{tabular}
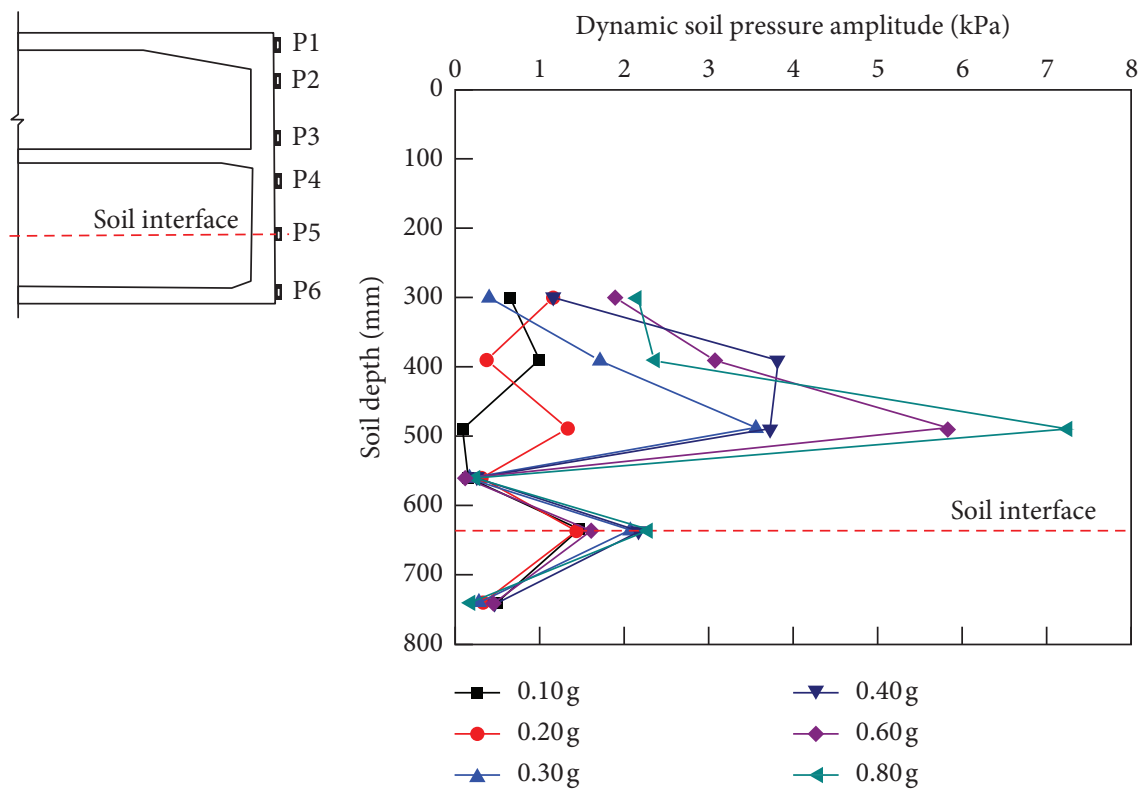

(a)

(b)

FIGURE 16: Dynamic soil pressure amplitude under the Kobe ground motion.

(2) The seismic response of the model structure and soil became more severe as the acceleration amplitude of the input motion increased. In addition, the increments of the acceleration, the dynamic soil pressure, and the strain became larger between adjacent cases under the Kobe record, indicating the 

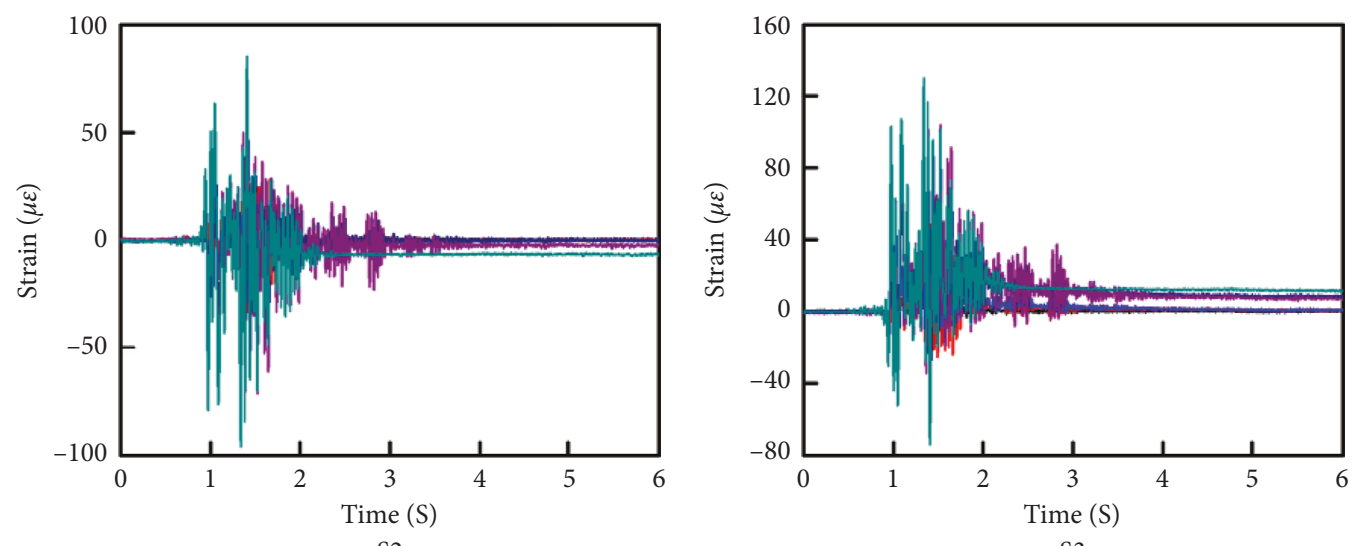

S2

S3

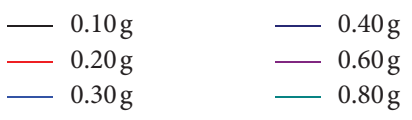

(a)
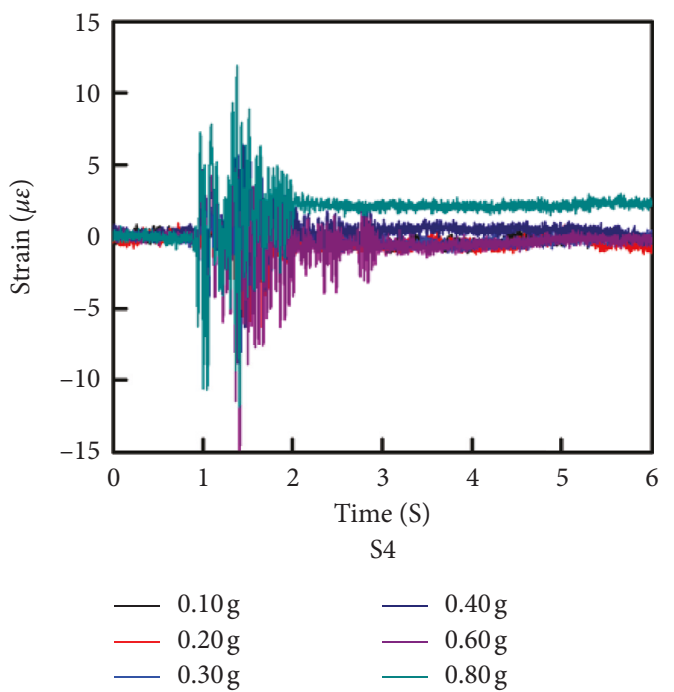

(c)

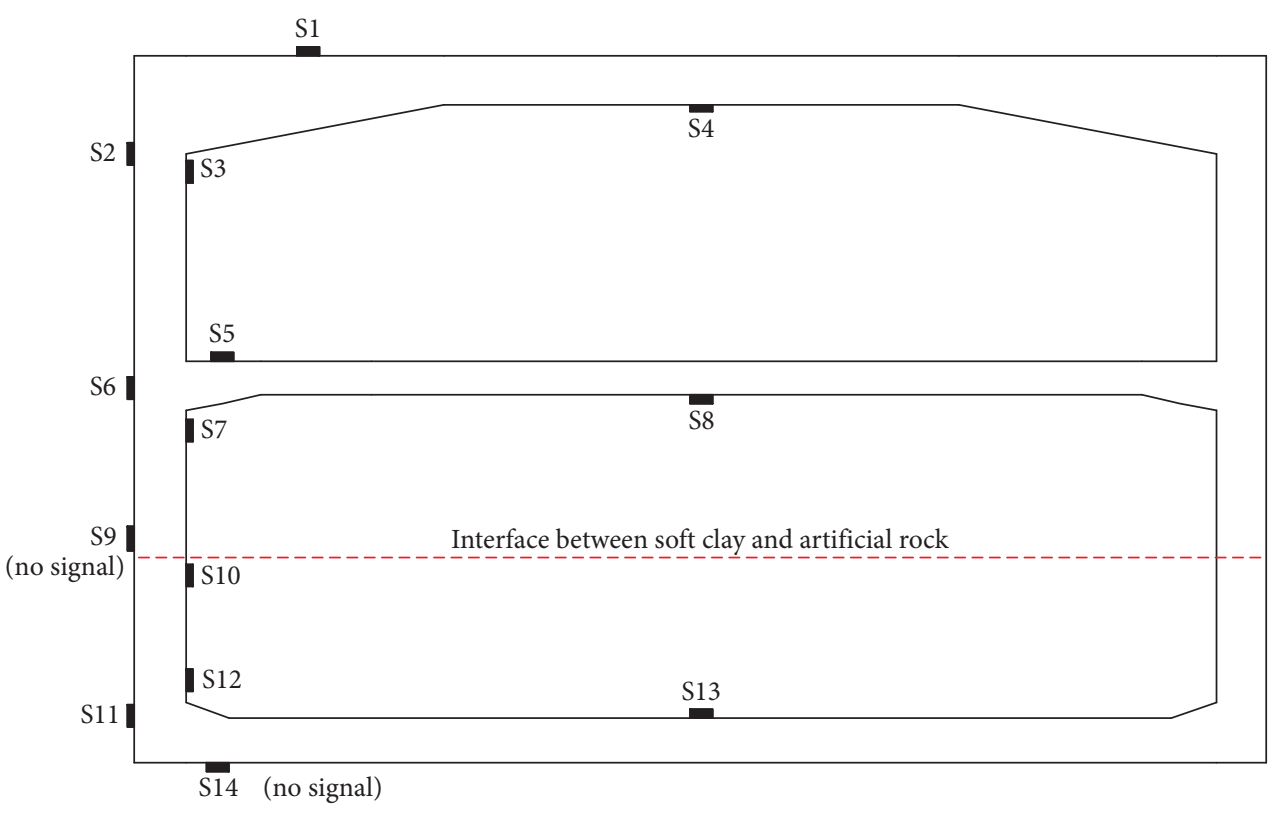

(e)

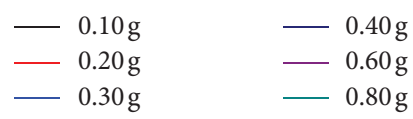

(b)

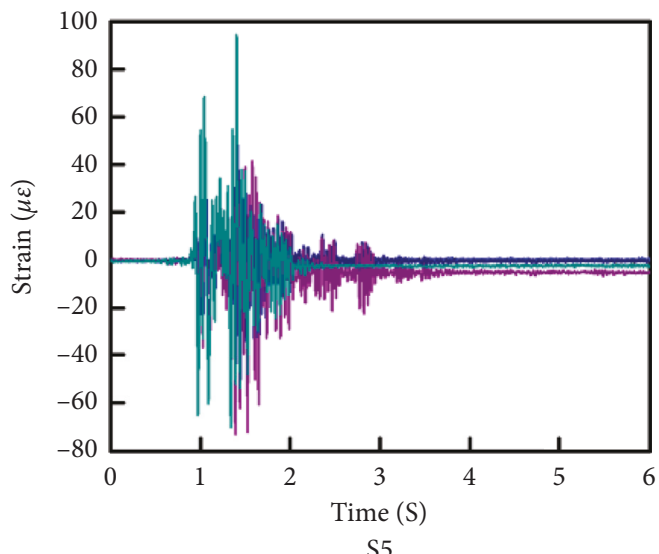

$0.10 \mathrm{~g}$
$-0.20 \mathrm{~g}$
$-0.30 \mathrm{~g}$

$-0.40 \mathrm{~g}$

$-0.60 \mathrm{~g}$ (d) 

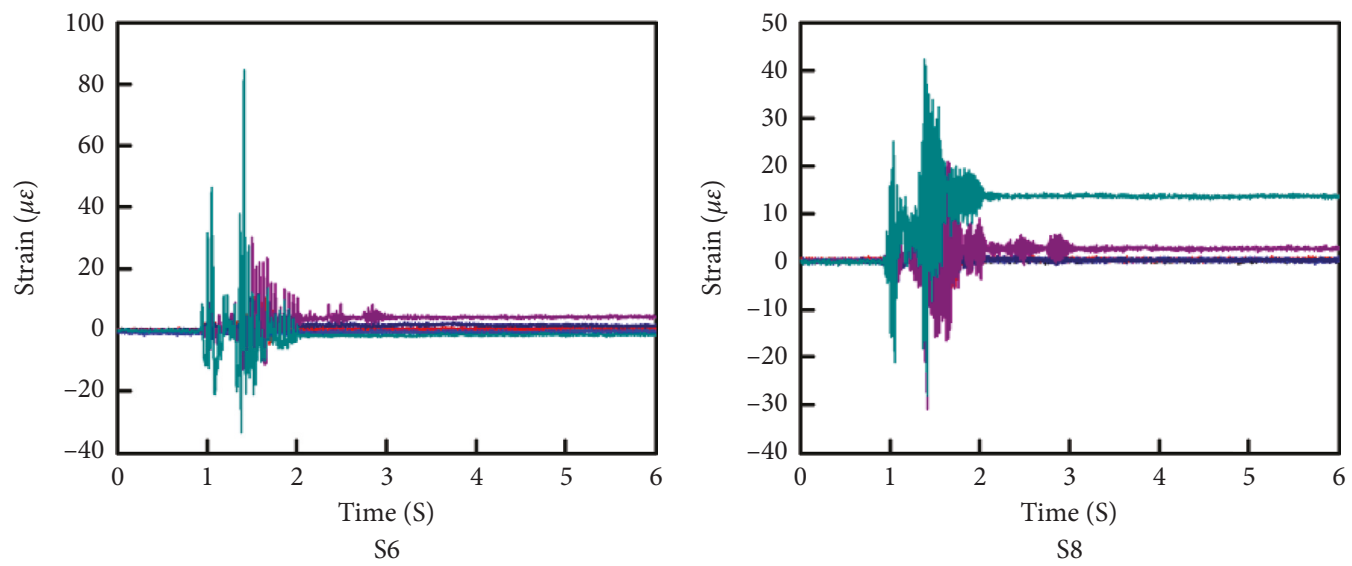

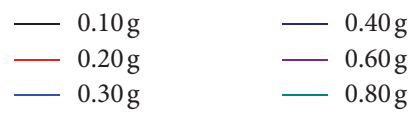

(f)
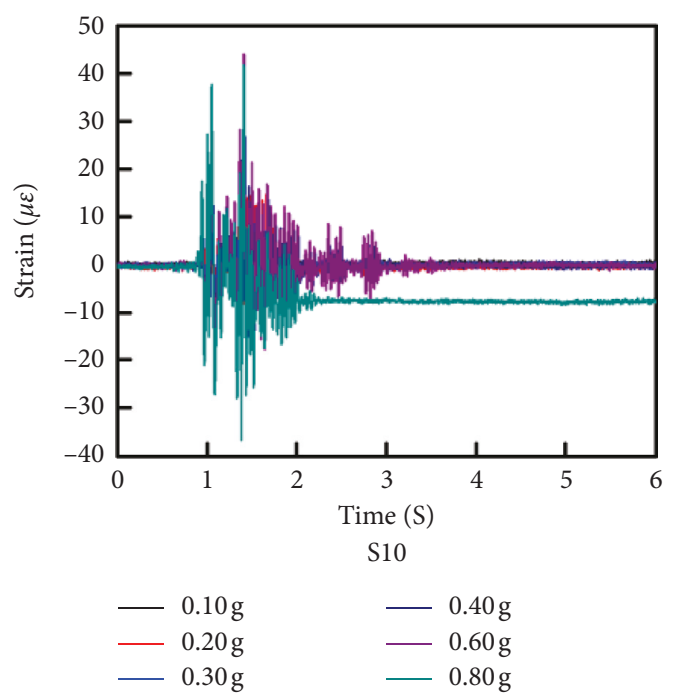

(h)

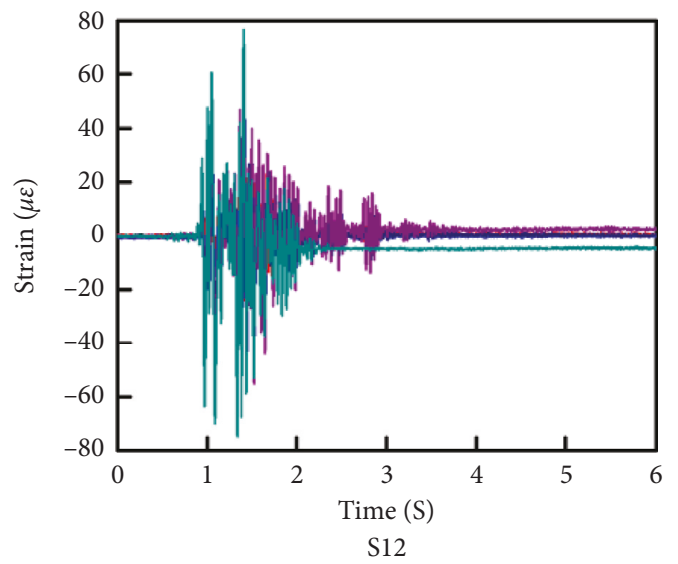

(j)

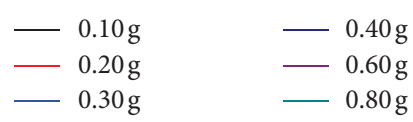

(g)

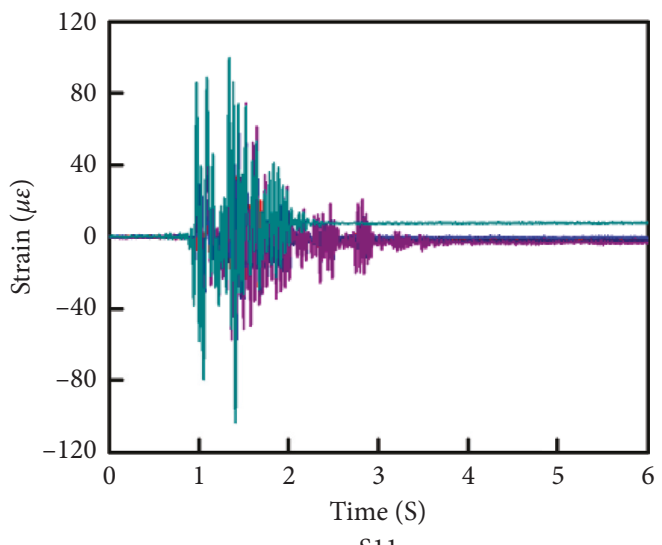

S11

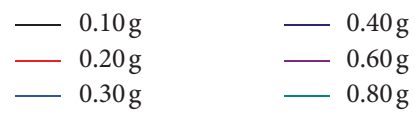

(i)

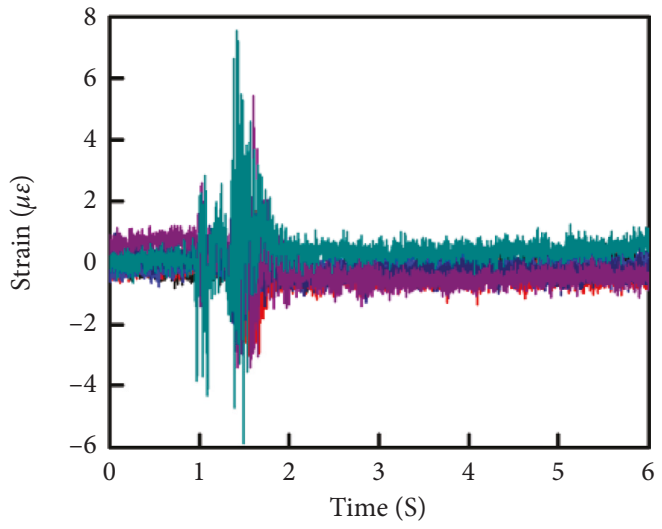

S13

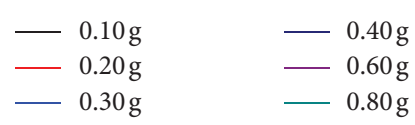

(k)

Figure 17: Time histories of the strain of the subway station structure under the Kobe ground motion. 


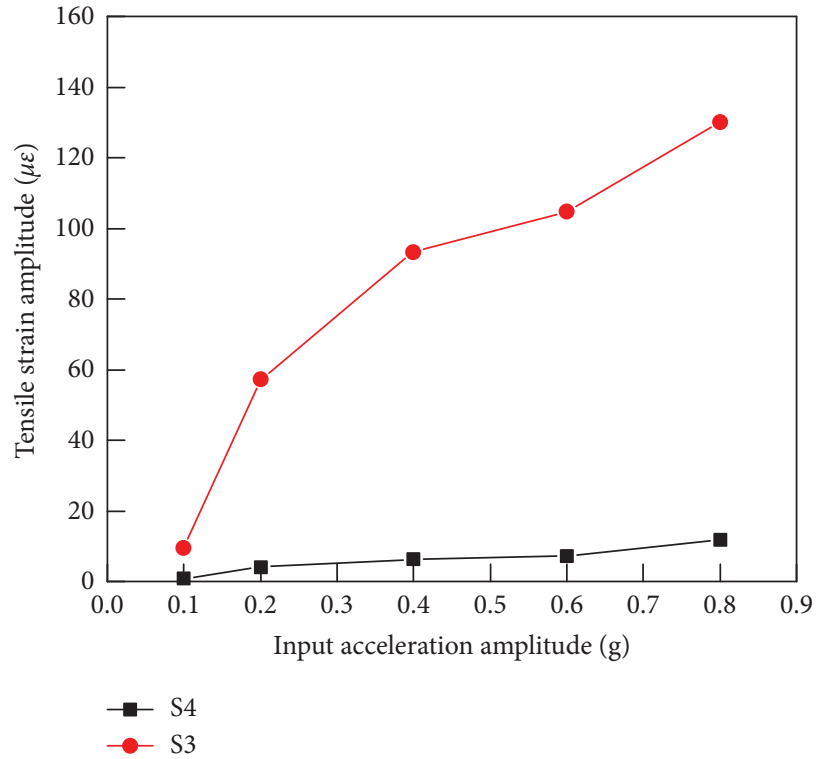

(a)

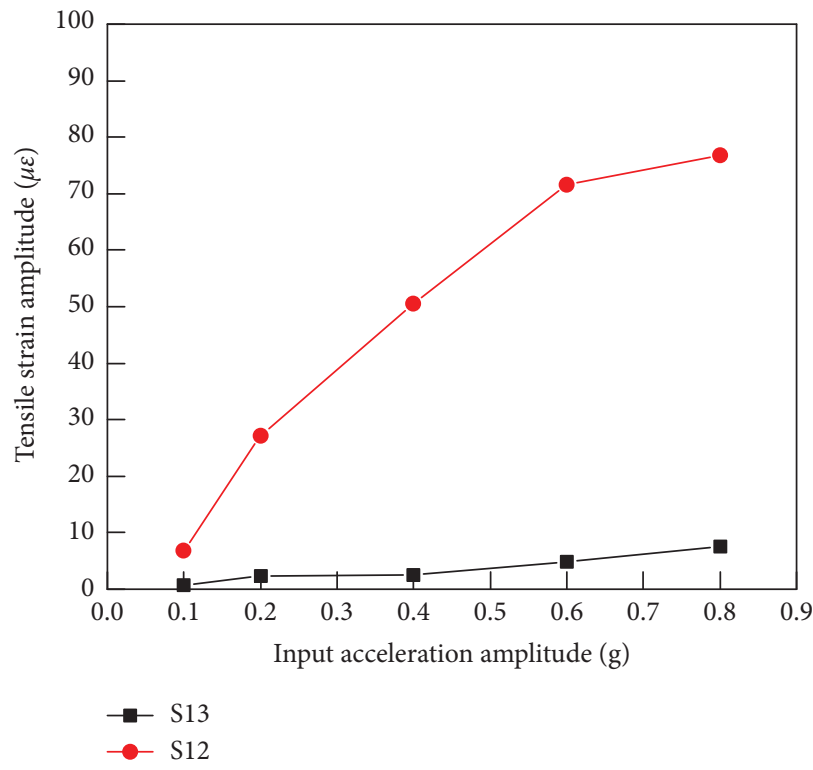

(c)

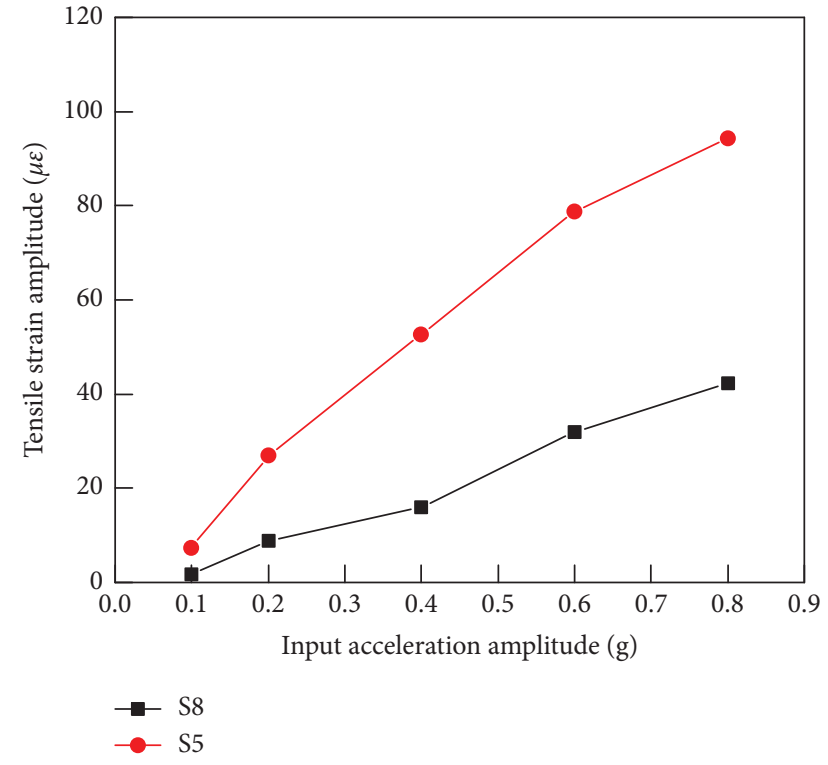

(b)

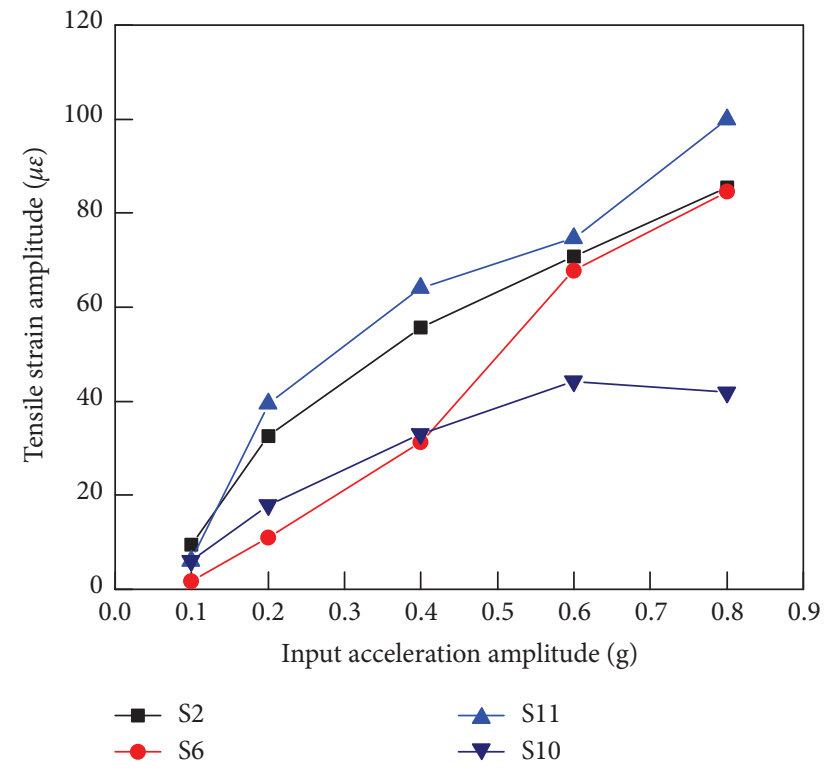

(d)

Figure 18: Tensile strain amplitude of the subway station structure under the Kobe ground motion. (a) Roof slab. (b) Middle slab. (c) Bottom slab. (d) Lateral wall.

possible shear damage of the soil and irreversible plastic deformation of the structure.

(3) The upper-soft and lower-hard composite strata had a significant effect on the seismic response of the model structure and soil. Upon the acceleration response, the amplification effect was more obvious in the soft clay than in the artificial rock. In addition, the dynamic soil pressure in the soft clay was larger than that in the artificial rock, and the "U-type" distribution of the dynamic soil pressure was clearly observed, manifesting greater deformation of the subway structure in the soft clay.
(4) For each component of the model structure, the tensile strain amplitude in the support region was larger than that in the midspan region. The support regions of the roof slab, lateral wall, and middle slab were the vulnerable components of the large-span and column-free subway station during an earthquake. Therefore, strengthening measures should be applied for these vulnerable components.

The seismic response of the subway station in the composite strata was very complicated because of various uncertainties in different soil layers and soil-structure interactions. It is very difficult to take all factors into account in 
the shaking table test. Hence, further improvements in the tests and numerical analysis should be attempted in future studies to understand the seismic performance of the largespan and column-free subway station in the composite strata.

\section{Data Availability}

The shaking table test data used to support the findings of this study are available from the corresponding author upon request.

\section{Conflicts of Interest}

The authors declare that there are no conflicts of interest regarding the publication of this paper.

\section{Acknowledgments}

This research was supported by the National Natural Science Foundation of China (Grant numbers 51678248 and 51878296) and the State Key Lab of Subtropical Building Science, South China University of Technology (Grant number 2017KB15).

\section{References}

[1] K. Uenishi and S. Sakurai, "Characteristic of the vertical seismic waves associated with the 1995 Hyogo-ken Nanbu (Kobe), Japan earthquake estimated from the failure of the Daikai underground station," Earthquake Engineering \& Structural Dynamics, vol. 29, no. 6, pp. 813-821, 2000.

[2] S. Nishiyama, K. Muroya, H. Haya, S. Tanamura, and A. Nishimura, "Seismic design of cut and cover tunnel based on damage analyses and experimental studies," Quarterly Report of RTRI, vol. 40, no. 3, pp. 158-164, 1999.

[3] T. Iwatate, Y. Kobayashi, H. Kusu et al., "Investigation and shaking table tests of subway structures of the HyogokenNanbu earthquake," in Proceedings of the 12th World Conference on Earthquake Engineering, pp. 1043-1051, New Zealand Society for Earthquake Engineering, Auckland, New Zealand, January-February 2000.

[4] A. Che and T. Iwatate, "Shaking table test and numerical simulation of seismic response of subway structures," Structures Under Shock \& Impact VII, vol. 11, no. 7, pp. 367-376, 2002.

[5] K. Ohtomo, T. Suehiro, T. Kawai et al., "Research on streamlining seismic safety ecaluation of underground reinforced concrete duct-type structures in nuclear power stations: experimental aspects of laminar shear sand box excitation tests with embedded RC models," Transactions, SMiRT, vol. 16, p. 1298, 2001.

[6] J. Matsui, K. Ohtomo, and K. Kanaya, "Development and validation of nonlinear dynamic analysis in seismic performance verification of underground RC structures," Journal of Advanced Concrete Technology, vol. 2, no. 1, pp. 25-35, 2004.

[7] Y. Tamari and I. Towhata, "Seismic soil-structure interaction of cross sections of flexible underground structures subjected to soil liquefaction," Soils and Foundations, vol. 43, no. 2, pp. 69-87, 2003.

[8] A.-1. Che, T. Iwatate, and X.-r. Ge, "Study on dynamic response of embedded long span corrugated steel culverts using scaled model shaking table tests and numerical analyses,"
Journal of Zhejiang University-Science A, vol. 7, no. 3, pp. 430-435, 2006.

[9] R. E. S. Moss and V. A. Crosariol, "Scale model shake table testing of an underground tunnel cross section in soft clay," Earthquake Spectra, vol. 29, no. 4, pp. 1413-1440, 2013.

[10] G. Chen, H. Zhuang, X. Du et al., "Large-scale shaking table test for subway station structure built in liquefiable saturated fine sand soil," Journal of Earthquake Engineering and Engineering Vibration, vol. 27, no. 3, pp. 163-170, 2007, in Chinese.

[11] G. Chen, X. Zuo, Z. Wang et al., "Shaking table test on seismic failure characteristics of subway station structure at liquefiable ground," Journal of Building Structure, vol. 33, no. 1, pp. 128-137, 2012, in Chinese.

[12] G. Chen, Z. Wang, X. Zuo, X. Du, and H. Gao, "Shaking table test on the seismic failure characteristics of a subway station structure on liquefiable ground," Earthquake Engineering \& Structural Dynamics, vol. 42, no. 10, pp. 1489-1507, 2013.

[13] G. Chen, S. Chen, C. Qi, X. Du, Z. Wang, and W. Chen, "Shaking table tests on a three-arch type subway station structure in a liquefiable soil," Bulletin of Earthquake Engineering, vol. 13, no. 6, pp. 1675-1701, 2015.

[14] G. Chen, S. Chen, X. Zuo, X. Du, C. Qi, and Z. Wang, "Shaking table tests and numerical simulations on a subway structure in soft soil," Soil Dynamics and Earthquake Engineering, vol. 76, pp. 13-28, 2015.

[15] L. Tao, P. Wang, and J. Bian, "A shaking table test on the representative subway station structure," Journal of Beijing University of Technology, vol. 9, pp. 798-801, 2006, in Chinese.

[16] L. Tao, B. Wu, and J. Li, "Shaking table test on Y-shaped column double-layer subway station," Railway Engineering, vol. 55, no. 9, pp. 36-40, 2014, in Chinese.

[17] Z. Chen, W. Chen, Y. Li, and Y. Yuan, "Shaking table test of a multi-story subway station under pulse-like ground motions," Soil Dynamics and Earthquake Engineering, vol. 82, pp. 111122, 2016.

[18] H. Zhuang, G. Chen, Z. Hu, and C. Qi, "Influence of soil liquefaction on the seismic response of a subway station in model tests," Bulletin of Engineering Geology and the Environment, vol. 75, no. 3, pp. 1169-1182, 2016.

[19] H. Zhuang, X. Wang, Y. Miao et al., "Seismic response of a subway station and tunnel in a slightly inclined liquefiable ground through shaking table test," Soil Dynamics and Earthquake Engineering, vol. 116, pp. 371-385, 2019.

[20] X. Qin and N. Chouw, "Shake table study on the effect of mainshock-aftershock sequences on structures with SFSI," Shock and Vibration, vol. 2017, Article ID 9850915, 12 pages, 2017.

[21] X.-F. Ma, N.-N. Feng, G.-B. Wang, and X. Fang, "Study on vibration reduction method for a subway station in soft ground," Shock and Vibration, vol. 2017, Article ID 4029385 , 9 pages, 2017.

[22] P. Moncarz and H. Krawinkler, "Theory and application of experimental model analysis in earthquake engineering," Report No. 50, Dept. of Civil Engineering and Environmental Engineering, Stanford University, Stanford, CA, USA, 1981. 


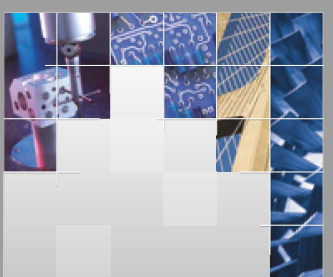

\section{Enfincering}
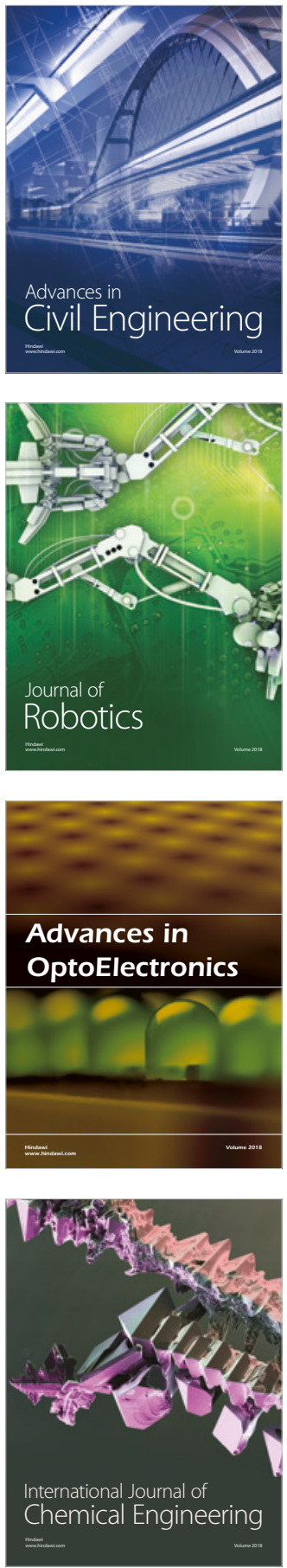

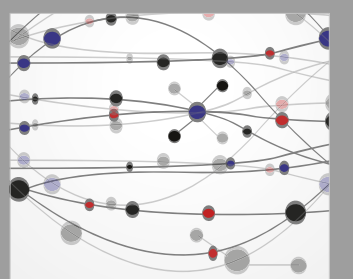

\section{Rotating \\ Machinery}

The Scientific World Journal

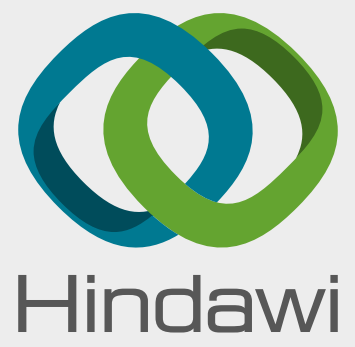

Submit your manuscripts at

www.hindawi.com
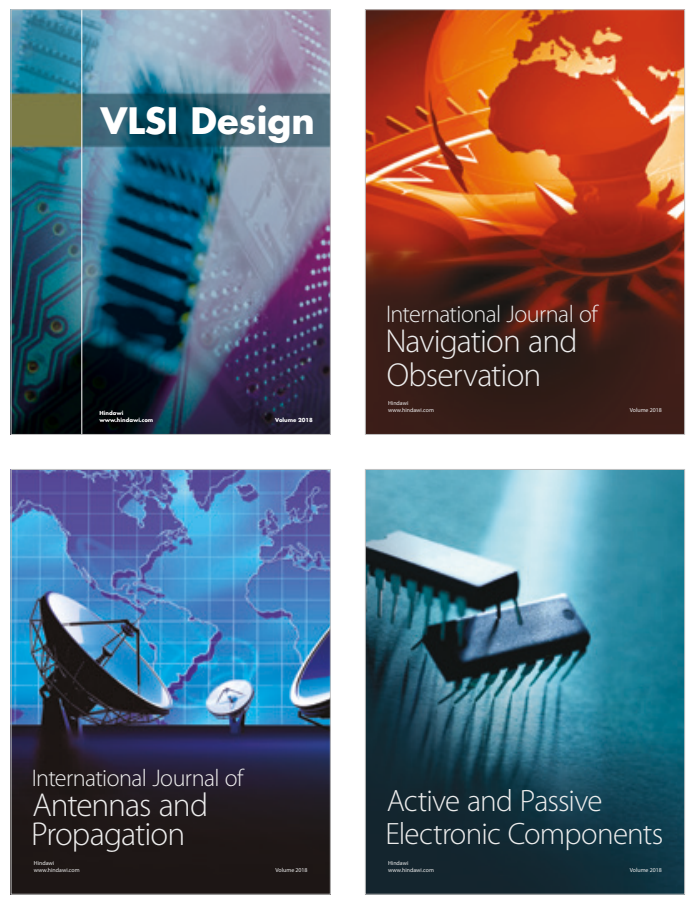
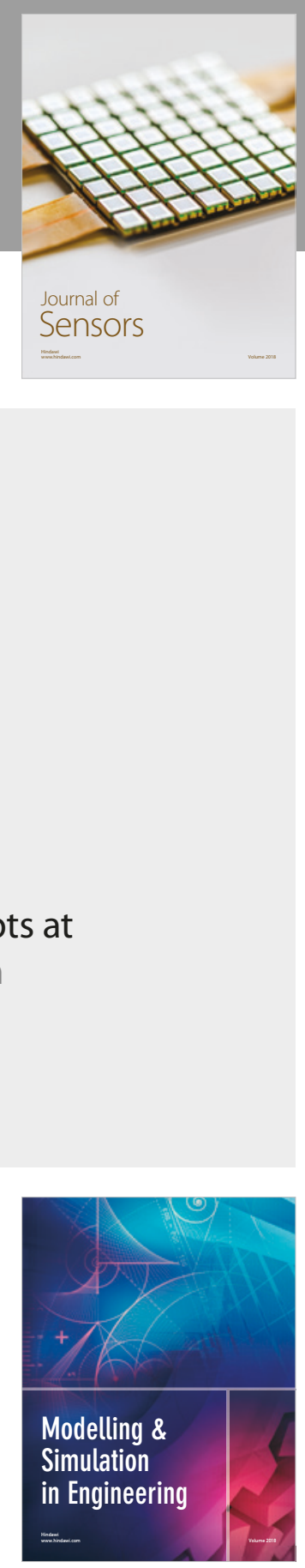

\section{Advances \\ Multimedia}
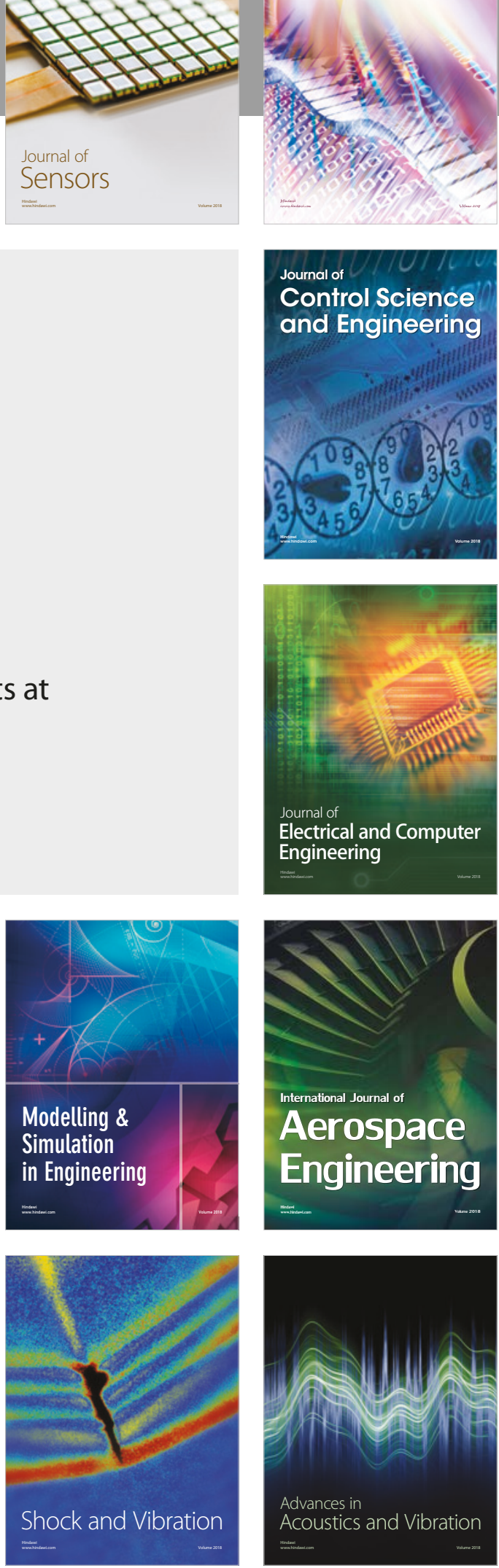